\title{
CHINESE JOURNAL OF PHYSICS
}

ISSN: 0577-9073; IMPACT FACTOR= 0514

PUBLISHER: ELSEVIER

Accepted August 20th 2017

\section{ANISOTROPIC SLIP MAGNETO-BIOCONVECTION FLOW FROM}

\section{A ROTATING CONE TO A NANOFLUID WITH STEFAN BLOWING EFFECTS}

\author{
F.T. Zohra ${ }^{a}$, M.J. Uddin ${ }^{B}$, A.I.M. Ismail ${ }^{c}$, O. Anwar Bég ${ }^{d}$, and A. Kadir ${ }^{e}$ \\ ${ }^{a}$ School of Mathematical Sciences, Universiti Sains Malaysia, 11800, Penang, Malaysia. \\ ${ }^{b}$ Mathematics Department, American International University, Banani, Dhaka, Bangladesh \\ ${ }^{d}$ Aeronautical and Mechanical Engineering Department, School of Computing, Science and \\ Engineering, Newton Building, University of Salford, M54WT, UK.
}

${ }^{b}$ Corresponding author: Email:jashim_74@yahoo.com

\begin{abstract}
A mathematical model for two dimensional steady laminar natural convective anisotropic slip boundary layer flows from a rotating vertical cone embedded in ethylene glycol bionanofluid is presented. The influence of Stefan blowing is also taken into account. Four different nonparticles namely Copper $(\mathrm{Cu})$, Alumina $\left(\mathrm{Al}_{2} \mathrm{O}_{3}\right)$, Copper Oxide $(\mathrm{Cuo})$, Titanium Oxide $\left(\mathrm{TiO}_{2}\right)$ are explored. Suitable similarity transformations are used to convert the governing equations into non-linear ordinary differential equations. These are then solved numerically, with appropriate boundary conditions, utilizing an implicit finite difference method (the BVP5C code in MATLAB). During computation $S c, L b, L e$ and $L b$ are presented as unity, whilst $\mathrm{Pr}$ is taken as 151 .The effects of the governing parameters on the dimensionless velocities, temperature, nanoparticle volume fraction, density of motile microorganisms as well as on the local skin friction, local Nusselt, Sherwood number and motile micro-organism number density are thoroughly examined via tables and graphs. It is found that the skin friction factor increases with tangential slip, magnetic field and Schmidt number whilst it decreases with blowing parameter and spin parameters. It is further observed that both the friction and heat transfer rates are highest for copper nanoparticles and lowest for $\mathrm{TiO}_{2}$ nanoparticles. Validation of the BVP5C numerical solutions with published results for several special cases of the general model is included. The study is relevant to electro-conductive bio-nano-materials processing.
\end{abstract}

KEY WORDS: Stefan blowing, bioconvection, rotating cone, BVP5C, anisotropic slip flow, bio-nanofluid; spin coating.

\section{INTRODUCTION}

To enhance the heat transfer properties (such as thermal conductivity) of conventional heat transfer fluids, nanoscale particles can be dispersed in the base fluids. These fluids, known as nanofluids, have received considerable attention from researchers. Commonly used base fluids include water, ethylene glycol and propylene. Theoretical and experimental studies of the 
performance of different nanoparticles such as $\mathrm{Al}_{2} \mathrm{O}_{3}, \mathrm{Cu}, \mathrm{CuO}, \mathrm{TiO}_{2}$ and $\mathrm{Ag}$ have been conducted by Akbarzadeh et al.[1], Oztop and Abu-Nada [2], Mebrouk et al.[3]. Several publications [4-7] on ethylene glycol as the base fluid have stressed that these fluids achieve better heat transfer properties which are advantageous for industrial and energy-saving devices. Hamida et al. [8] discussed the natural convective heat transfer in an enclosure filled with an ethyleneglycol-copper nanofluid under magnetic fields effects. Bio-nanofluids are synthesized by suspending micro-organisms in a nanofluid thereby enabling bioconvection to occur [9]. Bioconvection is due to motile microorganisms being generally heavier than water so that they are likely to swim in an upward direction and may induce unstable top heavy density stratification [10]. A series of studies has been carried out by Kuznetsov [11-12], Kuznetsov and Nield [13], Fang \& Tao [14] and $\mathrm{Xu}$ [15] on the applications and importance of bioconvection in thermo-bioconvection, microbial enhancement, biomicrosystems, biofuels and other bioengineering systems. These studies identified the combined advantages of both nanofluid and microorganism bioconvection which improve both heat transfer and mass transfer characteristics.

Surface mass flux i.e. blowing/injection is an established technique for modifying heat and mass transfer rates in external boundary layer convective heat and/or mass transfer. Suction/injection effects on free convective boundary layer flow from a cone were investigated by Watanabe [16]. Mass transfer (i.e. species transfer) along with heat transfer also exerts a significant role in for example manufacturing processes. Relevant studies in this regard have been communicated by Bhattacharyya and Layek [17] and Pal and Mondal [18]. There are situations where there is massive species transfer by evaporation. An example is paper drying processes. Species transfer or mass transfer can be a significant effect which can generate a "blowing effect" depending on the temperature and the water content of the wet paper sheet [19]. This blowing effect comes from the Stefan problem for species transfer. A bulk motion is produced by the diffusion of the species and this introduces an extra motion of the fluid. In the case of large mass transfer flux, for considering the blowing effects, a blowing factor can be used as a correction factor when interpreting results from studies which do not incorporate blowing effects. In the context of nanofluid flows, several investigators [20-22] examined the effects of Brownian diffusion and thermophoresis on heat and mass transfer rates. Extending this work, Rohni et al. [23], studied the flow and heat transfer over an unsteady shrinking sheet with suction in a nanofluid using Buongiorno's model. Hajmohammadi et al. [24] investigated and discussed the effects of $C u$ and $A g$ nanoparticles on flow and heat transfer from 
permeable surfaces, considering both suction and injection effects. Later Lattif et al.[10] studied the effect of Stefan blowing (surface injection) on bioconvective flow of nanofluid over a solid rotating stretchable disk.

Anisotropy is directional dependence and arises in many natural and manufactured materials. It is equally important in both solid and fluid mechanics. Anisotropic slip in fluid mechanics implies that the slip coefficient depends on the direction of flow, as elaborated by Wang [25]. Anisotropy is present if the surface being considered is composed of stick-slip strips in super hydrophobic applications [26-27] or when the surface has striated roughness. Anisotropic thermal and electrical properties of thin thermal interface layers of graphite nanoplatelet-based composites have been discussed in [28-29]. Raees et al. [30] studied the effect of anisotropic slip over a moving surface.

Heat transfer from a rotating vertical cone arises in many thermal engineering and materials synthesis operations including nuclear reactor cooling systems and spin coating etc. [31]. The fluid near the surface of the body is forced outward in the radial direction when an axisymmetric body rotates in a forced flow field. This is due to a centrifugal force. Thus the axial velocity of the fluid in the vicinity of a rotating body is higher than that of a stationary body. The convective heat transfer between the body and the fluid is therefore enhanced with this increase in the axial velocity [32]. Based on this principle, many systems for increasing heat transfer have been developed. Hering and Grosh [33] obtained similarity solutions for axisymmetrical steady convective laminar flow over a vertical cone. Their work has been extended by, among many others, [34-36]. Anilkumar and Roy [37] numerically simulated the unsteady mixed convection flow on a rotating cone. Ravindran et al. [31] analyzed mixed convection boundary layer flow with uniform suction or injection from a cone. Compressibility effects on laminar free convection flow over a vertical cone were examined computationally by Pop[36] and Bapuji et al.[38]. Magnetohydrodynamic unsteady mixed convection flow, heat and mass transfer over a rotating vertical cone were addressed in [32,39]. Free convection from a vertical permeable cone and free MHD flow convection from a vertical spinning cone were explored by Hossain et al. [40] and Narayana et al. [41], respectively. Recently Vanita \& Kumar [42] obtained numerical solutions for the effect of magnetic field on transient natural convection over a vertical cone. Hayat et al. [43] studied magnetohydrodynamic flow of burgers fluid with heat source and power law heat flux. In another paper Hayat et al. [44] discussed the application of non-Fourier heat flux theory in thermally stratified flow of second grade liquid with variable 
properties. Some recent papers on nanofluid and bioconvection are Das et al. [45], Giri et al. [46] and Acharaya et al. [47].

Thus far, to the authors' knowledge, no studies have been conveyed which address the Stefan blowing effects on steady anisotropic slip boundary layer flow from a rotating spinning cone to a bioconvection nanofluid. Motivated by new emerging applications in nano-bio-materials processing (spin coating), in this paper we extend the earlier studies of Bég et al. [43] and Uddin et al. [44]. Parameter values are extracted from Khan et al. [45] to investigate the flow, heat, mass and microorganism transfer characteristics. It is important to note that due to the blowing effects from mass transfer, the momentum and concentration equations become coupled and need to be solved simultaneously. The governing conservation equations are transformed into self-similar form and then solved as an ordinary differential two-point boundary layer problem using BVP5C in MATLAB. The effects of various flow parameters on the fluid flow, the skin friction factor, heat, mass and microorganism transfer are elaborated in detail.

\section{NANO-BIOCONVECTION FLUID MATHEMATICAL MODEL}

Axisymmetric, steady-state, laminar, Newtonian, incompressible, natural convective boundary layer anisotropic slip flow and bioconvection from a vertical rotating cone to a nanofluid is examined. Stefan blowing is present at the cone surface. The base fluid considered is ethylene glycol and the nanoparticles $\mathrm{Cu}, \mathrm{CuO}, \mathrm{Al}_{2} \mathrm{O}_{3}, \mathrm{TiO}$ are assumed to be in thermal equilibrium. The geometry of the problem is illustrated in Figure 1. Buoyancy forces are generated by temperature difference, concentration difference and also microorganism density number difference. Rotation is assumed to be sufficiently slow so that fluid compressibility effects can be ignored. The cone surface is isothermal. The $\bar{x}$-direction is parallel to the cone slant surface, the $\bar{y}$-direction normal to this and $\omega$-designates the angle in a plane perpendicular to the vertical symmetry axis. The cone is a representative geometry for chemical engineering mixing devices deployed in spin coating operations. $\gamma$ is the semi-vertex angle of the cone. A radial magnetic field is applied. The governing equations for the flow regime may be presented, with reference to a $(\bar{x}, \bar{y}, \omega)$ coordinate system by Bég et al. [43] and Uddin et al. [44], as follows:

\section{Mass:}

$$
\frac{\partial(\overline{r u})}{\partial \bar{x}}+\frac{\partial(\overline{r v})}{\partial \bar{y}}=0
$$




\section{Tangential Momentum:}

$$
\begin{aligned}
\rho_{n f}\left(\bar{u} \frac{\partial \bar{u}}{\partial \bar{x}}+\bar{v} \frac{\partial \bar{u}}{\partial \bar{y}}-\frac{\bar{w}^{2}}{\bar{x}}\right)= & \mu_{n f} \frac{\partial^{2} \bar{u}}{\partial \bar{y}^{2}}+\left(\rho \beta_{T}\right)_{n f} g \cos \gamma\left(T-T_{\infty}\right)+\left(\rho \beta_{C}\right)_{n f} g \cos \gamma\left(C-C_{\infty}\right) \\
& +\left(\rho \beta_{n}\right)_{n f} g \cos \gamma\left(n-n_{\infty}\right)-\sigma_{n f} B^{2} \bar{u}
\end{aligned}
$$

\section{Swirl Momentum:}

$\rho_{n f}\left(\bar{u} \frac{\partial \bar{w}}{\partial \bar{x}}+\bar{v} \frac{\partial \bar{w}}{\partial \bar{y}}+\frac{\bar{u} \bar{w}}{\bar{x}}\right)=\mu_{n f} \frac{\partial^{2} \bar{w}}{\partial \bar{y}^{2}}-\sigma_{n f} B^{2} \bar{w}$

Energy:

$\left(\rho C_{p}\right)_{n f}\left(\bar{u} \frac{\partial T}{\partial \bar{x}}+\bar{v} \frac{\partial T}{\partial \bar{y}}\right)=k_{n f} \frac{\partial^{2} T}{\partial \bar{y}^{2}}$

Species (Concentration):

$\bar{u} \frac{\partial C}{\partial \bar{x}}+\bar{v} \frac{\partial C}{\partial \bar{y}}=D_{B} \frac{\partial^{2} C}{\partial \bar{y}^{2}}$

Micro-organism species number density:

$\bar{u} \frac{\partial n}{\partial \bar{x}}+\bar{v} \frac{\partial n}{\partial \bar{y}}+\frac{\partial}{\partial \bar{y}}(n \tilde{v})=D_{n} \frac{\partial^{2} n}{\partial \bar{y}^{2}}$

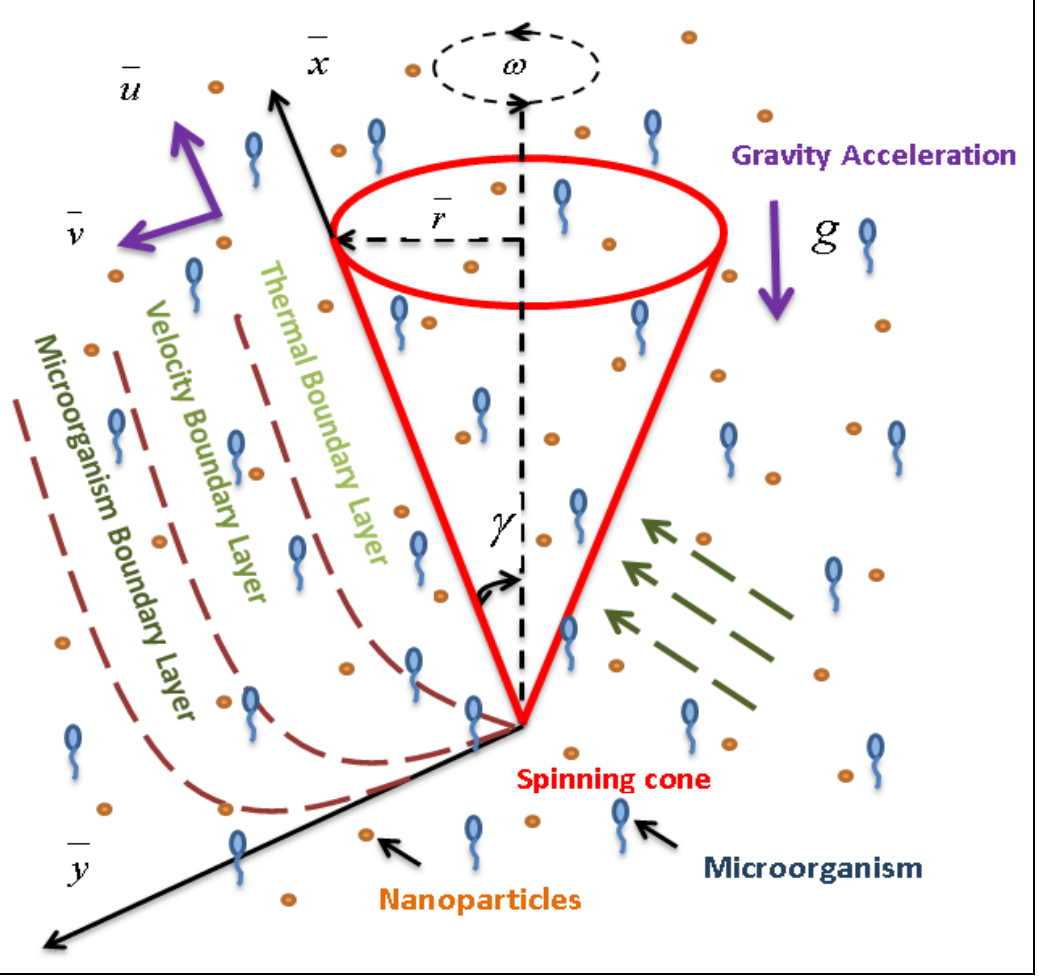

Figure 1: Physical model for nano-bioconvection flow from a rotating cone. 
The Boussinesq approximation has been used so that buoyancy effects only appear in the $\bar{x}$ direction momentum Eqn. (2), which is coupled to the energy, nano-particle species concentration equation and microorganism equations, so as to constitute a free convection regime. Viscous dissipation and cross-diffusion (Soret/Dufour) effects are ignored as is Joule dissipation. The corresponding boundary conditions at the surface and far from the cone [49] are as follows:

$$
\begin{aligned}
& \bar{u}=N_{1} v_{n f} \frac{\partial \bar{u}}{\partial \bar{y}}, \quad \bar{v}=-\frac{D}{(\bar{x} / L)\left(1-C_{w}\right)}\left(\frac{\partial C}{\partial \bar{y}}\right), \quad \bar{w}=\Omega \bar{r}+N_{2} v_{n f} \frac{\partial \bar{w}}{\partial \bar{y}}, \\
& T=T_{\infty}+\left(T_{w}-T_{\infty}\right)(\bar{x} / L)+D_{1} \frac{\partial T}{\partial \bar{y}}, \quad C=C_{\infty}+\left(C_{w}-C_{\infty}\right)(\bar{x} / L)+E_{1} \frac{\partial C}{\partial \bar{y}}, \\
& n=n_{\infty}+\left(n_{w}-n_{\infty}\right)(\bar{x} / L)+F_{1} \frac{\partial n}{\partial \bar{y}} \quad \text { at } \quad \bar{y}=0, \\
& \bar{u}=\bar{w}=0, \quad T=T_{\infty}, \quad C=C_{\infty}, \quad n=n_{\infty} \quad \text { as } \quad \bar{y} \rightarrow \infty .
\end{aligned}
$$

These boundary conditions address physically pertinent behavior at the wall and in the free stream. The three velocity components all have gradient conditions incorporated. The temperature, nano-particle concentration and micro-organisms density conditions are also scaled in terms of temperature gradient, concentration gradient and micro-organism gradient at the wall (cone surface). At the edge of the boundary layer vanishing velocity components are prescribed and vanishing nano-particle concentration, temperature and micro-organism density are imposed. These imply that the far-field region is cooled and progressively weaker doping of nano-particles and micro-organisms is applied as we progress from the wall to this far field (free stream) zone. These conditions have been deployed in various studies separately by Raees et al. [30] for nanofluid bioconvection flow and Narayana et al. [41] for rotational boundary layers. They have never been considered collectively as this embodies aspects of the novelty of the present investigation.

The properties of nanofluid are given by Oztopand Abu-Nada [2], Vajravelu et al. [51] and Sheikholeslami et al. [52] as follows: 


$$
\begin{aligned}
& v_{n f}=\frac{\mu_{n f}}{\rho_{n f}}=\frac{\mu_{f}}{(1-\Phi)^{2.5}\left[(1-\Phi) \rho_{f}+\Phi \rho_{s}\right]}, \quad \frac{\sigma_{n f}}{\sigma_{f}}=1+\frac{3 \Phi\left(\frac{\sigma_{s}}{\sigma_{f}}-1\right)}{\left(\frac{\sigma_{s}}{\sigma_{f}}+2\right)-\Phi\left(\frac{\sigma_{s}}{\sigma_{f}}-1\right)}, \\
& \left(\rho \beta_{T}\right)_{n f}=(1-\Phi)\left(\rho \beta_{T}\right)_{f}+\Phi\left(\rho \beta_{T}\right)_{s}, \quad\left(\rho \beta_{C}\right)_{n f}=(1-\Phi)\left(\rho \beta_{C}\right)_{f}+\Phi\left(\rho \beta_{C}\right)_{s}, \\
& \left(\rho \beta_{n}\right)_{n f}=(1-\Phi)\left(\rho \beta_{n}\right)_{f}+\Phi\left(\rho \beta_{n}\right)_{s}, \quad\left(\rho C_{p}\right)_{n f}=(1-\Phi)\left(\rho C_{p}\right)_{f}+\Phi\left(\rho C_{p}\right)_{s},(8) \\
& \alpha_{n f}=\frac{k_{n f}}{\left(\rho C_{p}\right)_{n f}}, \quad \frac{k_{n f}}{k_{f}}=\frac{\left(k_{s}+2 k_{f}\right)-2 \Phi\left(k_{f}-2 k_{s}\right)}{\left(k_{s}+2 k_{f}\right)+\Phi\left(k_{f}-2 k_{s}\right)}, \quad B=\frac{B_{0} b_{0}(x)}{r \sqrt{1-\left(r^{\prime}\right)^{2}}} \\
& \tilde{v}=\frac{b W_{C}}{\Delta C} \cdot \frac{\partial C}{\partial \bar{y}}\left(\frac{L}{\bar{x}}\right) .
\end{aligned}
$$

The thermophysical properties of base fluid(i.e. Ethylene Glycol) and different nanoparticles are given in Table 1taken from Hamida and Charrada [8] and Mutuku [53].As described by

\begin{tabular}{|c|c|c|c|c|c|c|c|}
\hline Materials & $\operatorname{Pr}$ & $\begin{array}{l}\rho \\
\left(\mathrm{kg} / \mathrm{m}^{3}\right)\end{array}$ & $\begin{array}{l}C_{p} \\
(\mathrm{~J} / \mathrm{kgK})\end{array}$ & $\begin{array}{l}K \\
(W / m K)\end{array}$ & $\begin{array}{l}\beta \times 10^{-5} \\
\left(\frac{1}{K}\right)\end{array}$ & $\begin{array}{l}\alpha \times 10^{-5} \\
\left(m^{2} / s\right)\end{array}$ & $\begin{array}{l}\sigma \\
(S / m)\end{array}$ \\
\hline $\begin{array}{l}\text { Ethylene-glycol } \\
\left(\mathrm{C}_{2} \mathrm{H}_{6} \mathrm{O}_{2}\right)\end{array}$ & 151 & 1109 & 2400 & 0.26 & 65 & 1.0214 & $5.5 \times 10^{-6}$ \\
\hline $\begin{array}{l}\text { Copper oxide } \\
(\mathrm{CuO})\end{array}$ & & 6500 & 535.6 & 20 & 0.85 & 0.57 & $5.96 \times 10^{7}$ \\
\hline $\begin{array}{l}\text { Alumina } \\
\left(\mathrm{Al}_{2} \mathrm{O}_{3}\right)\end{array}$ & & 3970 & 765 & 40 & 0.85 & 1.3 & $3.5 \times 10^{7}$ \\
\hline Titania $\left(\mathrm{TiO}_{2}\right)$ & & 4250 & 686.2 & 8.9538 & 0.9 & 0.31 & $2.38 \times 10^{6}$ \\
\hline Copper $(\mathrm{Cu})$ & & 8933 & 385 & 401 & 1.67 & 11.7 & $5.8 \times 10^{7}$ \\
\hline
\end{tabular}
Uddin et al. [49], for uniform roughness, $N_{1}=N_{2}$ (e.g. spinning disk used in reaction vessels), whilst for concentric grooves, $N_{1}<N_{2}$ (e.g. phonograph record), for radial grooves, $N_{1}>N_{2}$ (e.g. brake disks). Here we consider $N_{1}>N_{2}$.

Table 1. Thermophysical properties of Ethyleneglycol and nanoparticles. 
The boundary layer Eqns. (1) to (6) are strongly coupled, parabolic and nonlinear. An analytical solution is not tractable and in order to obtain a robust solution, we next non-dimensionalize the model. We introduce the following transformations:

$$
\begin{aligned}
& x=\frac{\bar{x}}{L}, \quad y=\frac{\bar{y}}{L G r_{L}^{-1 / 4}}, \quad r=\frac{\bar{r}}{L}, \quad u=\frac{\bar{u}}{U}, \quad v=\frac{\bar{v}}{U G r^{-1 / 4}}, \quad w=\frac{\bar{w}}{\Omega L}, \\
& U=\left[g \cos \gamma\left(\beta_{T}\right)_{f} L\left(T_{w}-T_{\infty}\right)\right]^{1 / 2}, \theta=\frac{T-T_{\infty}}{T_{w}-T_{\infty}}, \phi=\frac{C-C_{\infty}}{C_{w}-C_{\infty}}, \chi=\frac{n-n_{\infty}}{n_{w}-n_{\infty}} .
\end{aligned}
$$

The transport equations are thereby reduced to the following dimensionless equations:

$$
\begin{aligned}
& \frac{\partial(r u)}{\partial x}+\frac{\partial(r v)}{\partial y}=0 \\
& u \frac{\partial u}{\partial x}+v \frac{\partial u}{\partial y}-\frac{\operatorname{Re}^{2}}{G r} \frac{w^{2}}{x}=A_{0} \frac{\partial^{2} u}{\partial y^{2}}+A_{1}\left(\tilde{\theta}+N_{C} \phi+N_{n} \tilde{\chi}\right)-A_{2} M \Lambda^{2} u \\
& u \frac{\partial w}{\partial x}+v \frac{\partial w}{\partial y}+\frac{u w}{x}=A_{0} \frac{\partial^{2} w}{\partial y^{2}}-A_{2} M \Lambda^{2} w \\
& u \frac{\partial \theta}{\partial x}+v \frac{\partial \theta}{\partial y}=\frac{1}{\operatorname{Pr}} A_{3} \frac{\partial^{2} \theta}{\partial y^{2}} \\
& u \frac{\partial \phi}{\partial x}+v \frac{\partial \phi}{\partial y}=\frac{1}{S c} \frac{\partial^{2} \phi}{\partial y^{2}} \\
& u \frac{\partial \tilde{\chi}}{\partial x}+v \frac{\partial \tilde{\chi}}{\partial y}=\frac{1}{L b} \frac{\partial^{2} \tilde{\chi}}{\partial y^{2}}-\frac{P e}{L b} \cdot \frac{1}{x}\left[\frac{\partial \tilde{\chi}}{\partial y} \cdot \frac{\partial \phi}{\partial y}+\tilde{\chi} \frac{\partial^{2} \phi}{\partial y^{2}}\right]
\end{aligned}
$$

The boundary conditions are also transformed to:

$$
\begin{aligned}
& v=-\frac{s}{S c \cdot x} \frac{\partial \phi}{\partial y}, \quad u=A_{0} \delta_{u} \frac{\partial u}{\partial y}, \quad w=r+A_{4} \delta_{u} \frac{\partial w}{\partial y}, \quad \theta=x+\delta_{t} \frac{\partial \theta}{\partial y}, \\
& \phi=x+\delta_{C} \frac{\partial \phi}{\partial y}, \quad \chi=x+\delta_{n} \frac{\partial \chi}{\partial y} \quad \text { at } \quad y=0 \\
& u=w=\tilde{\theta}=\phi=\tilde{\chi}=0 \quad \text { as } \quad y \rightarrow \infty .
\end{aligned}
$$

In these equations the constants $A_{i}(i=0,1,2, \ldots 4)$ are defined as follows:

$$
A_{0}=\frac{1}{(1-\Phi)^{2.5}\left[1-\Phi+\Phi \frac{\rho_{s}}{\rho_{f}}\right]}, A_{1}=\frac{1-\Phi+\Phi \frac{(\rho \beta)_{s}}{(\rho \beta)_{f}}}{1-\Phi+\Phi \frac{\rho_{s}}{\rho_{f}}}, A_{2}=\frac{\left[1+\frac{3 \Phi\left(\frac{\sigma_{s}}{\sigma_{f}}-1\right)}{\left(\frac{\sigma_{s}}{\sigma_{f}}+2\right)-\Phi\left(\frac{\sigma_{s}}{\sigma_{f}}-1\right)}\right]}{1-\Phi+\Phi \frac{\rho_{s}}{\rho_{f}}},
$$


$A_{3}=\frac{k_{n f} / k_{f}}{1-\Phi+\Phi \frac{\left(\rho C_{p}\right)_{s}}{\left(\rho C_{p}\right)_{f}}}, A_{4}=\frac{1}{1-\Phi+\Phi \frac{\rho_{s}}{\rho_{f}}}, N_{n}=\frac{\left(\rho \beta_{n}\right)_{f}}{\left(\rho \beta_{T}\right)_{f}} \frac{n_{w}-n_{\infty}}{T_{w}-T_{\infty}}$, is the microorganism-tothermal-buoyancy ratio parameter, $N_{C}=\frac{\left(\rho \beta_{C}\right)_{f}}{\left(\rho \beta_{T}\right)_{f}} \frac{C_{w}-C_{\infty}}{T_{w}-T_{\infty}}$, is the concentration-to-thermalbuoyancy ratio parameter, $M=\frac{B_{0}^{2} L \sigma_{f}}{U \rho_{f}}$, is the magnetic parameter (i.e. ratio of magnetic drag force to inertial body force), $\Lambda=\frac{b_{0}(x)}{r \sqrt{1-\left(r^{\prime}\right)^{2}}}$, is the magnetic field function, $s=\frac{C_{w}-C_{\infty}}{1-C_{\infty}}$, is the suction or injection parameter, $S c=\frac{v_{f}}{D_{B}}$, is the Schmidt number (ratio of viscous diffusion rate to species diffusive rate of nano-particles in the boundary layer), $\operatorname{Pr}=\frac{v_{f}}{\alpha_{f}}$, is the Prandtl number (ratio of viscous diffusion rate to thermal (heat) diffusive rate in the boundary layer), $\mathrm{P} e=\frac{b W_{c}}{D_{n}}$, is the bioconvection Péclet number (which correlates the rate of advection of a flow to the micro-organisms rate of diffusion), $L b=\frac{v_{f}}{D_{n}}$, is the Lewis number ( ratio of viscous diffusion arte to micro-organism diffusion rate), $\operatorname{Re}=\frac{\Omega L^{2}}{v_{f}}$, is the rotational Reynolds number (ratio of Coriolis body force to the viscous hydrodynamic force), $G r=\left(\frac{U L}{v_{f}}\right)^{2}$, is the Grashof number, $\delta_{u}=N_{1} \sqrt{\frac{U v_{f}}{L}}$, is the tangential slip parameter, $\delta_{r}=N_{2} \sqrt{\frac{U v_{f}}{L}}$, is the swirl slip parameter, $\delta_{t}=D_{1} \sqrt{\frac{U}{L v_{f}}}$, is the thermal slip parameter, $\delta_{C}=E_{1} \sqrt{\frac{U}{L v_{f}}}$, is the mass slip parameter and $\delta_{n}=F_{1} \sqrt{\frac{U}{L v_{f}}}$ is the microorganism slip parameter. 
The non-dimensional Eqns. (10) to (17) can be simplified further by using appropriate similarity transformations. We first define a dimensional stream function, $\psi$, following Ece (2006) [54] :

$r u=\frac{\partial \psi}{\partial y}, r v=-\frac{\partial \psi}{\partial x}$.

The boundary layer variables are now re-scaled with $r=x \sin \gamma$, as follows:

$\psi=x r f(\eta), \quad \eta=y \quad w=r h(\eta), \tilde{\theta}=x \theta(\eta), \quad \phi=x \phi(\eta), \quad \tilde{\chi}=x \chi(\eta)$.

Introducing these relations into Eqns. (10)-(17), generates the following $11^{\text {th }}$ order system of "self-similar" ordinary differential equations:

$$
\begin{aligned}
& A_{0} f^{\prime \prime \prime}+2 f f^{\prime \prime}-\left(f^{\prime}\right)^{2}-A_{2} M \Lambda^{2} f^{\prime}+N_{R} h^{2}+A_{1}\left(\theta+N_{c} \phi+N_{n} \chi\right)=0, \\
& A_{0} h^{\prime \prime}+2 f h^{\prime}-2 h f^{\prime}-A_{2} M \Lambda^{2} h=0, \\
& A_{3} \theta^{\prime \prime}+\operatorname{Pr}\left(2 f \theta^{\prime}-f^{\prime} \theta\right)=0, \\
& \phi^{\prime \prime}+\operatorname{Sc}\left(2 f \phi^{\prime}-f^{\prime} \phi\right)=0 \\
& \chi^{\prime \prime}-\operatorname{Pe}\left(\chi \phi^{\prime \prime}+\chi^{\prime} \phi^{\prime}\right)-\operatorname{Lb}\left(\chi f^{\prime}-2 f \chi^{\prime}\right)=0
\end{aligned}
$$

The transformed boundary conditions for the current problem take the form:

$$
\begin{aligned}
& f(0)=\frac{s}{2 S c} \phi^{\prime}(0), \quad f^{\prime}(0)=A_{0} \delta_{u} f^{\prime \prime}(0), \quad h(0)=1+A_{4} \delta_{r} h^{\prime}(0), \\
& \theta(0)=1+\delta_{t} \theta^{\prime}(0), \quad \phi(0)=1+\delta_{C} \phi^{\prime}(0), \quad \chi(0)=1+\delta_{n} \chi^{\prime}(0), \\
& f^{\prime}(\infty) \rightarrow 0, \quad h(\infty) \rightarrow 0, \quad \theta(\infty) \rightarrow 0, \quad \phi(\infty) \rightarrow 0, \quad \chi(\infty) \rightarrow 0,
\end{aligned}
$$

where $N_{R}=\frac{(\operatorname{Re} \sin \gamma)^{2}}{G r}$ is the rotational (spin) parameter.

\section{ENGINEERING DESIGN QUANTITIES}

The quantities of interest in the present problem are the skin friction coefficient, $C_{f \bar{x}}$, the local Nusselt number, $N u_{\bar{x}}$, the local Sherwood number, $S h_{\bar{x}}$ and the density number of motile micro-organisms, $N n_{\bar{x}}$. These parameters characterize the surface drag, heat, mass and density number motile micro-organism transfer rates respectively. These are defined respectively as: 


$$
C_{f_{\bar{x}}}=\frac{\tau_{w}}{\frac{1}{2} \rho_{n f} U^{2}}, \quad N u_{\bar{x}}=\frac{L}{k_{n f}} \frac{q_{w}}{\left(T_{w}-T_{\infty}\right)}, \quad S h_{\bar{x}}=\frac{L}{D_{B}} \frac{J_{w}}{\left(C_{w}-C_{\infty}\right)}, \quad N n_{\bar{x}}=\frac{L}{D_{n}} \frac{P_{w}}{\left(n_{w}-n_{\infty}\right)},
$$

where $\tau_{w}, q_{w}, J_{w}, P_{w}$ represents the shearing stress at the surface of the cone, surface heat flux, surface mass flux and surface motile micro-organism flux respectively and defined as follows [41]:

$$
\begin{aligned}
& \tau_{w}=\mu_{n f}\left[\frac{\partial \bar{u}}{\partial \bar{y}}\right]_{\bar{y}=0}=\frac{\mu_{n f} U}{L G r^{-1 / 4}} x f^{\prime \prime}(0), \quad q_{w}=-k_{n f}\left[\frac{\partial T}{\partial \bar{y}}\right]_{\bar{y}=0}=\frac{-k_{n f}\left(T_{w}-T_{\infty}\right)}{L G r^{-1 / 4}} x \theta^{\prime}(0), \\
& q_{w}=-k_{n f}\left[\frac{\partial T}{\partial \bar{y}}\right]_{\bar{y}=0}=\frac{-k_{n f}\left(T_{w}-T_{\infty}\right)}{L G r^{-1 / 4}} x \theta^{\prime}(0), \quad J_{w}=-D_{B}\left[\frac{\partial C}{\partial \bar{y}}\right]_{\bar{y}=0}=\frac{-D_{B}\left(C_{w}-C_{\infty}\right)}{L G r^{-1 / 4}} x \varphi^{\prime}(0),
\end{aligned}
$$

Using Eqn. (27) in Eqn.(26), we obtain

$$
\begin{aligned}
& C_{f_{\bar{x}}} G r^{1 / 4}=A_{0} 2 x f^{\prime \prime}(0), \quad N u_{-} G r^{-1 / 4}=-x \theta^{\prime}(0), \\
& S h_{\bar{x}} G r^{-1 / 4}=-x \varphi^{\prime}(0), \quad N n_{\bar{x}} G r^{-1 / 4}=-x \chi^{\prime}(0),
\end{aligned}
$$

\section{RESULTS AND DISCUSSION}

The transport problem amounts to a $11^{\text {th }}$ order system of nonlinear, multi-degree, ordinary differential equations defined by (20)-(24) with boundary conditions (25). This boundary value problem is solved computationally using the BVP5C code in MATLAB.BVP5C is a finite difference computational code using the three-stage Lobatto IIIA formula. It is a collocation scheme that provides a continuous solution with uniformly fifth-order accuracy. Features such as mesh selection and error control are included in the code. Further details are provided in Hairer et al. [55].

Validation of the present numerical method i.e., BVP5C has been conducted with existing solutions in the technical literature. The mathematical model defined by eqns. (20)-(24) with boundary conditions (25), in the absence of a porous medium, micro-organism equation and magnetic field (i.e. $M=0$ ) reduces to the case considered by Uddin et al. [49] for a conventional fluid $(\Phi=0)$. To validate our solution method, Tables $\mathbf{2 , 3}$ provides a comparison between the current results and those of Ece [54] and Uddin et al.[49]. Inspection of the tables shows that very good agreement is achieved and therefore confidence in the present BVP5C solutions is justifiably high.

Table 2: Values of $f^{\prime \prime}(0)$ for free-convection boundary-layer flow over a spinning cone with (purely fluid case), $\delta_{u}=\delta_{r}=\delta_{t}=0$. 


\begin{tabular}{|l|l|l|l|l|l|}
\hline & $N_{R}$ & & KBM & $\begin{array}{l}\text { Maple17 } \\
\text { Uddin } \text { et al. [44] }\end{array}$ & $\begin{array}{l}\text { BVP5C } \\
\text { (Present) }\end{array}$ \\
\hline \multirow{3}{*}{$\operatorname{Pr}=1$} & 0 & 0.68150212 & 0.6814929 & 0.6814833 & 0.681445228 \\
\cline { 2 - 6 } & 0.5 & 0.84650616 & 0.8464987 & 0.8464882 & 0.846461574 \\
\cline { 2 - 6 } & 1.0 & 1.00196008 & 1.0020111 & 1.0019431 & 1.001923466 \\
\cline { 2 - 6 } & 2.0 & 1.29230021 & 1.2924014 & 1.2922849 & 1.292273184 \\
\hline \multirow{3}{*}{$\operatorname{Pr}=10$} & 0 & 0.43327726 & 0.4321874 & 0.4291876 & 0.433145326 \\
\cline { 2 - 6 } & 0.5 & 0.62601869 & 0.6230851 & 0.6228014 & 0.625907572 \\
\cline { 2 - 6 } & 1.0 & 0.79828572 & 0.7983791 & 0.798418104 & 0.798213797 \\
\cline { 2 - 6 } & 2.0 & 1.10990481 & 1.1098976 & 1.10990496 & 1.109868639 \\
\hline
\end{tabular}

Table 3: Values of $-\theta^{\prime}(0)$ for free-convection boundary-layer flow over a spinning cone with (purely fluid case), $\delta_{u}=\delta_{r}=\delta_{t}=0$.

\begin{tabular}{|c|c|c|c|c|c|}
\hline & $N_{R}$ & Ece [54] & $\begin{array}{l}\text { KBM } \\
\text { Uddin et al. [49] }\end{array}$ & $\begin{array}{l}\text { Maple17 } \\
\text { Uddin et al. [49] }\end{array}$ & $\begin{array}{l}\text { BVP5C } \\
\text { (Present) }\end{array}$ \\
\hline \multirow{4}{*}{$\operatorname{Pr}=1$} & 0 & 0.63886614 & 0.63886429 & 0.63885470 & 0.638813262 \\
\hline & 0.5 & 0.67194897 & 0.67194871 & 0.67193844 & 0.671909573 \\
\hline & 1.0 & 0.70053401 & 0.70053387 & 0.70052453 & 0.700503571 \\
\hline & 2.0 & 0.74869559 & 0.74869472 & 0.74868824 & 0.748676247 \\
\hline \multirow{4}{*}{$\operatorname{Pr}=10$} & 0 & 1.27552680 & 1.27552692 & 1.26598645 & 1.275192304 \\
\hline & 0.5 & 1.47165986 & 1.47165994 & 1.547638332 & 1.471468900 \\
\hline & 1.0 & 1.60768499 & 1.60768489 & 1.20756132 & 1.607583275 \\
\hline & 2.0 & 1.80575019 & 1.80575025 & 1.80574943 & 1.805709674 \\
\hline
\end{tabular}

Extensive computations are conducted to simulate the variation of the non-dimensional tangential velocity $\left(f^{\prime}\right)$, swirl velocity $(h)$, temperature $(\theta)$, nano-particle concentration $(\phi)$, microorganism species number density $(\chi)$ with distance $(\eta)$, into the boundary layer. Although sixteen thermophysical parameters are featured in the model, we examine explicitly the effects of only twelve, namely, $N_{R}, \delta_{n}, \delta_{c}, \delta_{t}, \delta_{r}, \delta_{u}, s,(s<0$ for suction, $s>0$ for injection i.e. Stefan blowing, and $s=0$ for solid cone), $\Lambda, M, N_{n}, N_{C}$ and $\Phi$. During computation $L b, P e$ Pr and $S c$ are prescribed fixed values which correspond to ethylene glycol 
based fluid. $S c, L b, L e, L b$ are prescribed as 1 , whilst $\operatorname{Pr}$ is 151 .All computations are conducted with BVP5C and are illustrated in Figs. 2-13. The maximum far field boundary is prescribed at $\eta=6$ to ensure asymptotically smooth solutions are attained in the free steam.

2(a)

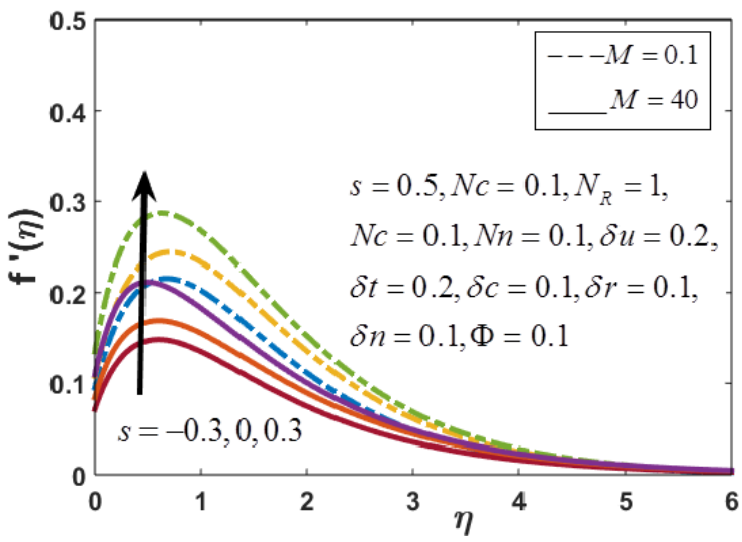

2(c)

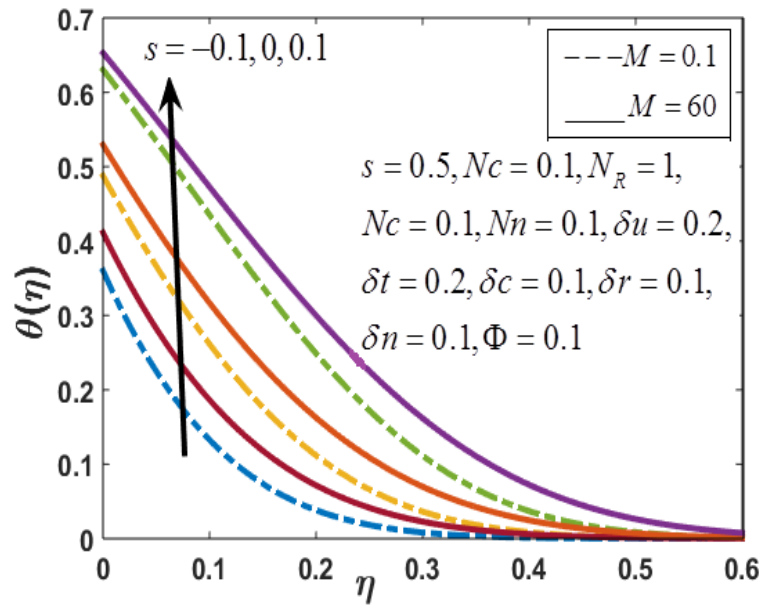

2(b)

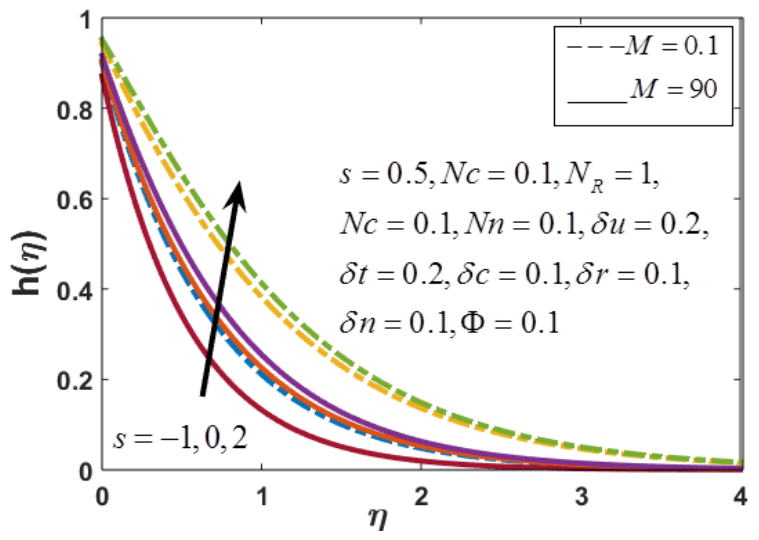

2(d)

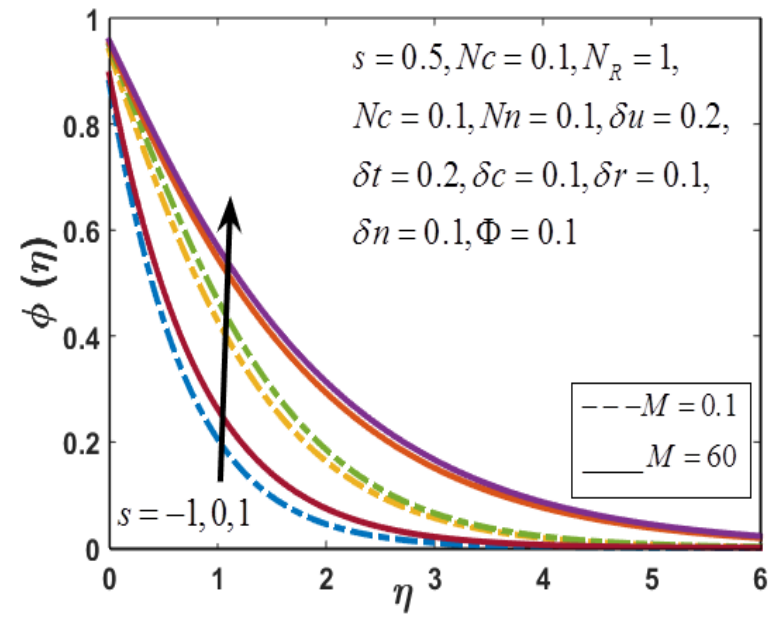

2(e)

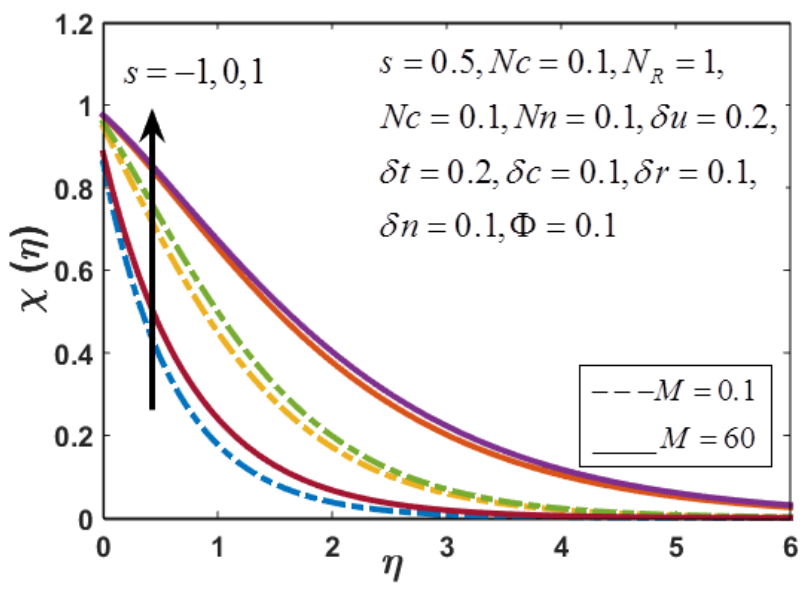


Figure 2:Effects of $M$ and $s$ on (a) tangential velocity, (b) swirl velocity,(c) temperature, (d) concentration, and (e) micro-organism species number density profiles for $\mathrm{Al}_{2} \mathrm{O}_{3}$ nanofluid.

Fig.2 show sthe effects of surface transpiration (associated with the perforated cone) on tangential velocity, swirl velocity, temperature, concentration and microorganism species number density, respectively. Significant deviations in profiles are observed in velocity profiles (Fig. 2(a, b)). Tangential profiles are parabolic-they ascend from the cone surface, attain a maximum a short distance therefrom, and then descend smoothly to vanish in the free stream. Swirl profiles, however, follow a consistent monotonic decay from the cone surface to the free stream. With greater suction $(s<0)$, both velocity fields are suppressed; with greater injection i.e. Stefan blowing $(s>0)$, they are both accelerated. The case of the solid cone (no transpiration) naturally falls between the suction and injection (blowing) cases. Suction clearly causes adhesion of the boundary layer to the cone surface, and this at sufficiently high rotational Reynolds numbers will delay boundary layer separation. Injection adds momentum to the boundary layer regime and encourages greater viscous diffusion, of interest in spin coating operations. Farther from the wall, significantly greater tangential velocity magnitudes are computed compared with swirl velocity magnitudes, even though the latter are greater in the near-wall zone. Whereas with the increase of the magnetic field effect the opposite outline is detected, as both the tangential and swirl velocity profiles decreases following the same pattern as of surface transpiration. Fig. 2(c-d) demonstrates that temperature, concentration and microorganism species number density decay from maximum values at the wall (cone surface) to the free stream, irrespective of the wall transpiration effect. Greater suction, however reduces temperature, concentration and microorganism species density number values, although larger magnitudes of concentration are apparent over the entire region transverse to the cone surface. Greater injection values are found to assist thermal and species diffusion, thereby elevating thermal, concentration and microorganism species density number boundary layer thickness. The destruction of momentum associated with larger wall suction is principally responsible for the reduction in heat, mass and microorganism diffusion, with the opposite effect sustained for injection. With the increase of the magnetic field, temperature concentration and microorganism species density number profiles increase following the same pattern as of surface transpiration. A similar pattern is also observed by Uddin et al. [49]. 
3(a)

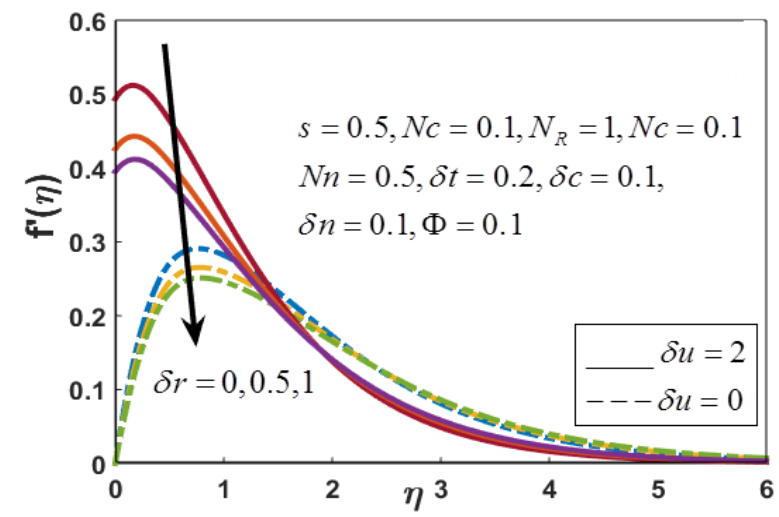

3(c)

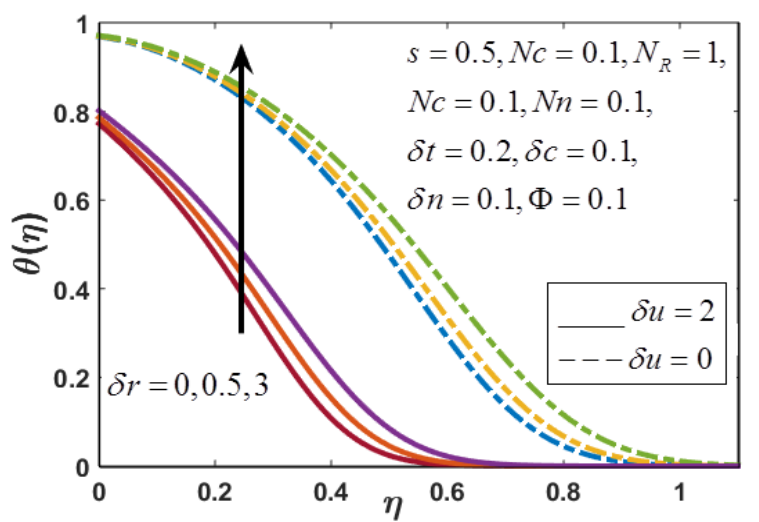

3(b)

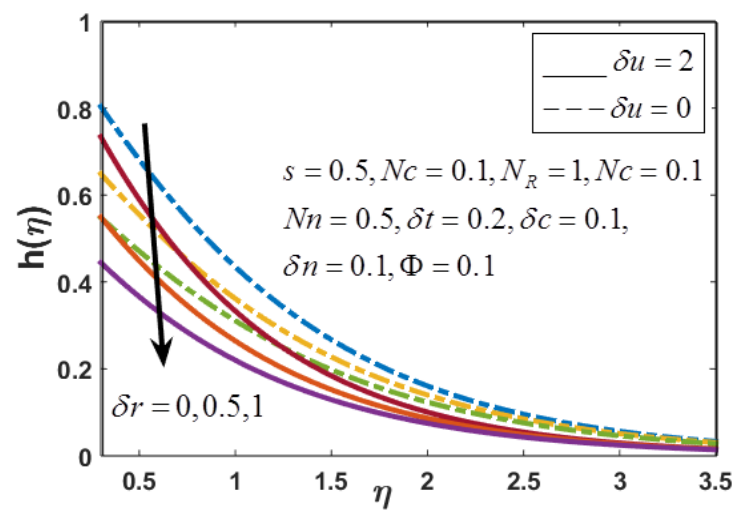

3(d)

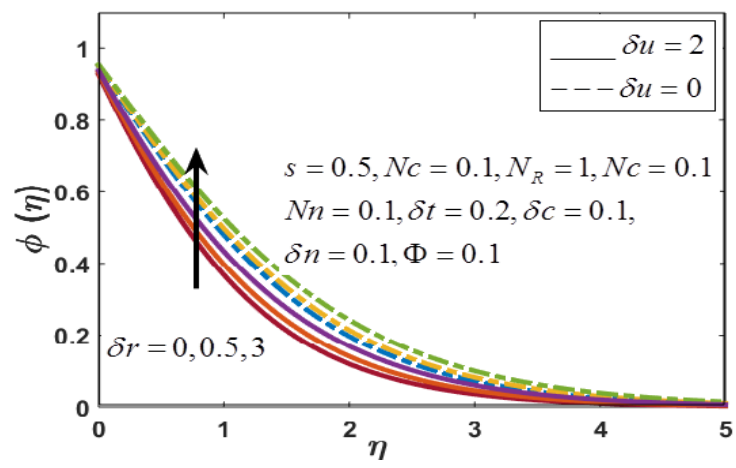

3(e)

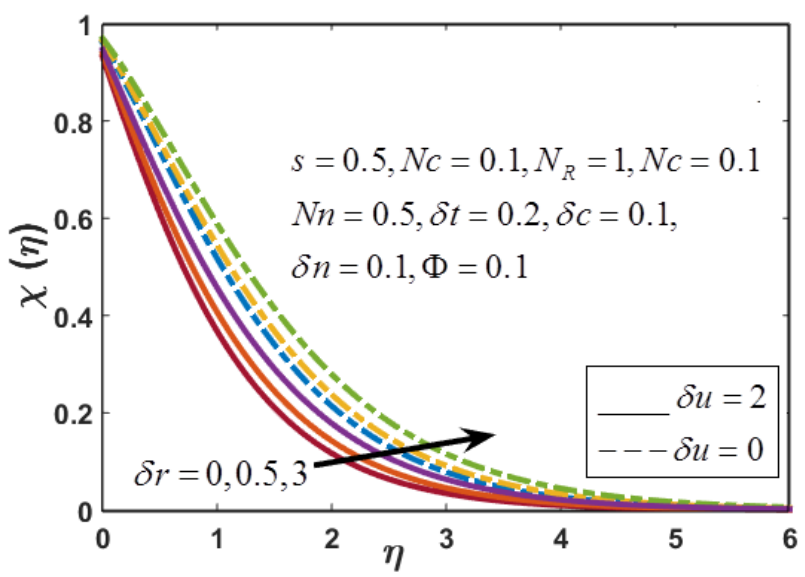

Figure 3: Effects of $\delta_{u}$ and $\delta_{r}$ on (a) tangential velocity,(b) swirl velocity,(c) temperature,(d) concentration, and (e) microorganism species number density profiles for $\mathrm{Al}_{2} \mathrm{O}_{3}$ nanofluid. 
Fig. 3 illustrates the influence $\delta_{u}$ and $\delta_{r}$ on flow characteristics. Tangential velocity is observed to experience a strong acceleration with greater slip for injection case, whereas swirl flow is damped (Fig. 3 (a) \& (b)). As tangential slip increases, the tangential near-wall peak is progressively displaced closer to the cone surface. However, since the tangential flow is dominant, it draws the greater part of momentum from the swirl field and thereby depletes the latter. The boost in tangential flow is therefore primarily aided with greater momentum slip, whereas the swirl flow is further retarded. With increasing momentum slip parameter; temperature, concentration and microorganism species density number is weakly decreased. Conversely with increasing swirl slip parameter; tangential velocity, temperature, concentration and microorganism species density number profile demonstrate the opposite response. That is, tangential and swirl velocities decreases and temperature, concentration, microorganism species density number increases with the increase of swirl slip parameter.

4(a)

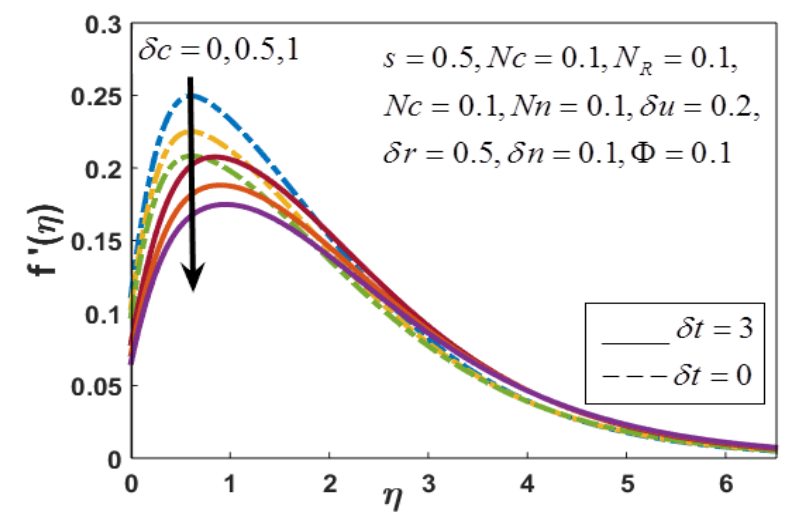

4(b)

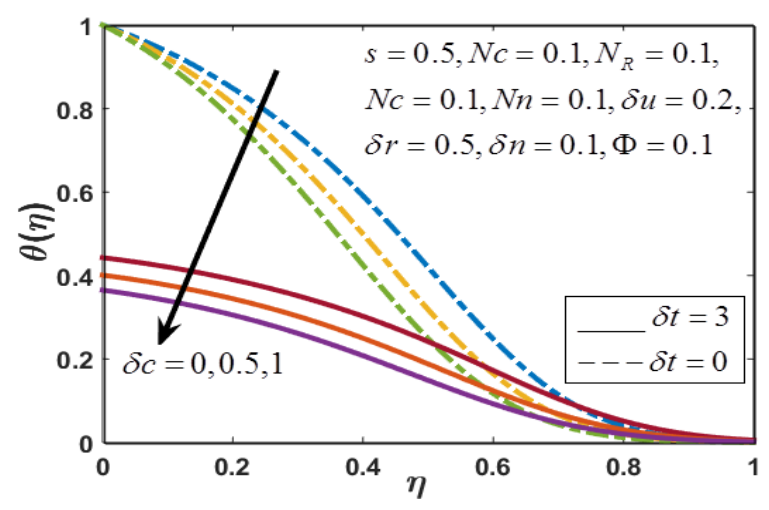




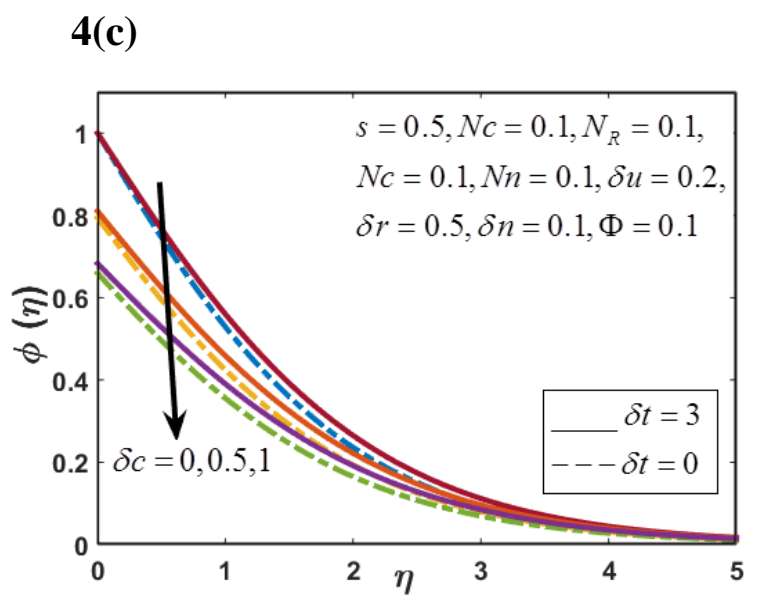

Figure 4: Effects of $\delta_{t}$ and $\delta_{c}$ on(a) tangential velocity,(b) temperature, and(c) concentration profiles for $\mathrm{Al}_{2} \mathrm{O}_{3}$ nanofluid.

Fig. 4 presents the effect of thermal slip parameter, $\delta_{t}$, and mass slip parameter, $\delta_{c}$ on the velocity function, temperature and concentration function distributions. Thermal slip parameter features only in the augmented wall temperature condition in eqn. (25). It will therefore have a pronounced effect on temperatures which it strongly reduces (Fig. 4(b)) but will indirectly (via coupling of all the boundary layer equations to each other) also impart an effect on velocity and concentration fields. In Fig. 4(a) we observe that this is indeed the case-tangential flow is seen to be strongly suppressed, with the peak again migrating for stronger thermal slip closer to the cone surface. Whereas the concentration is enhanced somewhat throughout the boundary layer transverse to the wall Fig. 4(c), temperatures are very substantially decreased, in particular at the cone surface. Cooling of the cone surface is therefore achieved successfully with the thermal slip effect. Figs 4a-calso depict the response of the species concentration to solutal (mass) slip parameter, $\delta_{c}$. As anticipated this parameter, solely arising in the modified wall condition for concentration in eqn. (25) has very little influence on tangential and swirl velocity or temperatures (graphs are therefore omitted) and microorganism species number density, despite the coupling of the concentration field to the tangential field. With greater mass slip, there is a marked depression in concentration magnitudes, especially at the wall (cone surface) and this effect is transferred into the boundary layer, although it weakens progressively with further distance from the wall. Evidently therefore species diffusion in the boundary layer is non-trivially decreased with greater mass slip and this will manifest in a thinning in species boundary layer thickness. Similarly the 
temperature and tangential velocity profiles also both decrease with an increase in mass slip parameter.

5(a)

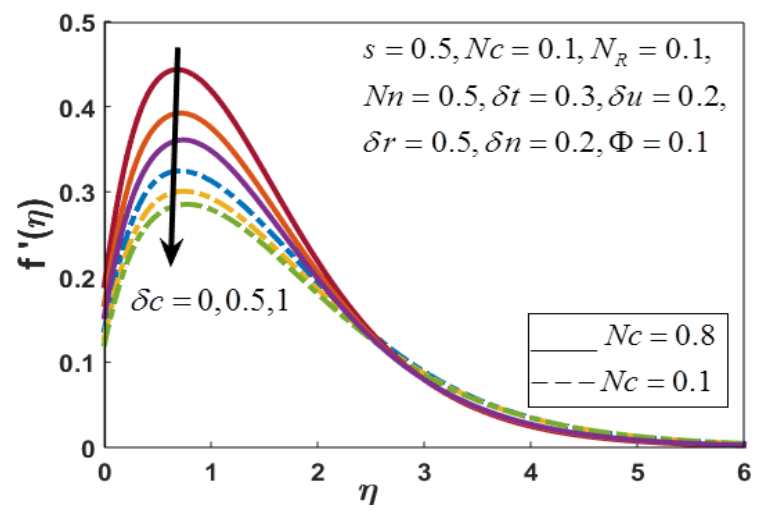

5(b)

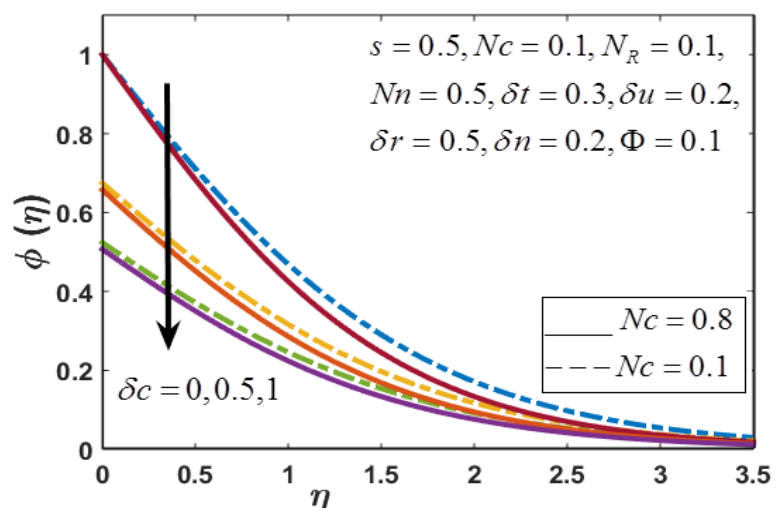

Figure 5: Effects of $\delta_{c}$ and $N_{c}$ on (a) tangential velocity, (b) concentration profiles for $\mathrm{Al}_{2} \mathrm{O}_{3}$ nanofluid.

Fig. 5 presents the influence of mass slip parameter $\delta_{c}$ and concentration-to-thermalbuoyancy ratio parameter, $N_{c}$, on tangential velocity, $f^{\prime}$ and concentration, $\phi . N_{c}$ represents the relative influence of species buoyancy force compared with thermal buoyancy force and is a critical parameter in double-diffusive (thermo-solutal) convection flows. When $N_{c}=0$ purely forced convection heat and mass transfer arises. For $N_{c}>1$ species buoyancy dominates thermal buoyancy and vice versa for $N_{c}>1$. Greater $N_{c}$ values are found to greatly accentuate the tangential flow (Fig. 5(a)). Concentration is depressed and species boundary layer thicknesses are reduced with greater buoyancy ratio (Fig. 5(b)). With the increase of mass slip parameter both the tangential velocity and concentration profiles decrease. 
6(a)

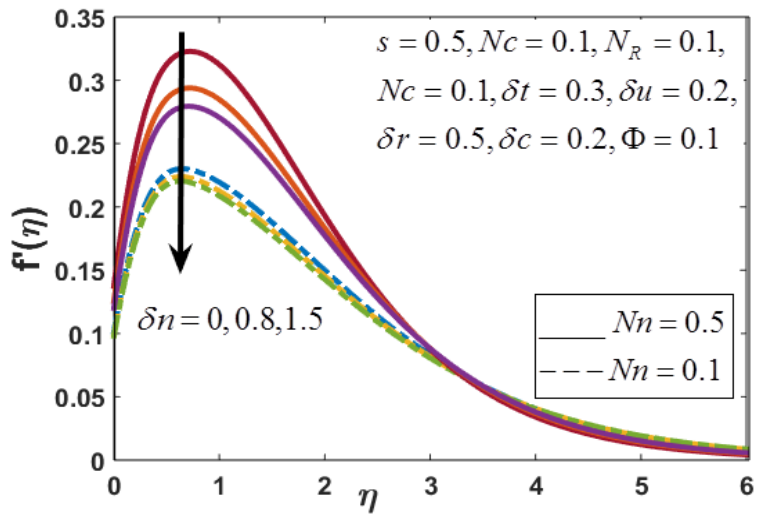

6(b)

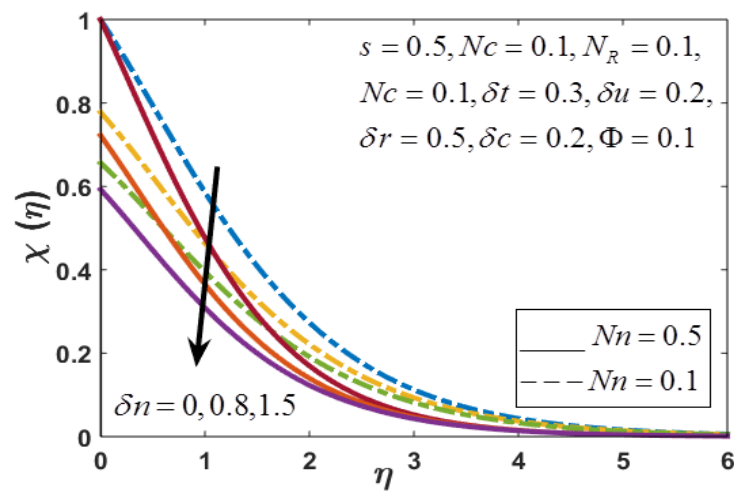

Figure 6: Effects of $\delta_{n}$ and $N_{n}$ on(a) tangential velocity, and (b) microorganism species number density profiles for $\mathrm{Al}_{2} \mathrm{O}_{3}$ nanofluid.

Fig. 6 presents the influence of microorganism slip parameter $\delta_{n}$ and microorganism-tothermal-buoyancy ratio parameter, $N_{n}$, on tangential velocity, $f^{\prime}$ and microorganism species number density, $\chi \cdot N_{n}$ represents the relative influence of micro-organism buoyancy force compared with thermal buoyancy force. Greater $N_{n}$ values are found to greatly accentuate the tangential flow (Fig. 6(a)). Microorganism species number density is depressed and species boundary layer thickness is reduced with greater buoyancy ratio (Fig. 6(b)). However with an increase in micro-organism slip parameter both the tangential velocity and microorganism species number density values are reduced. 
7(a)

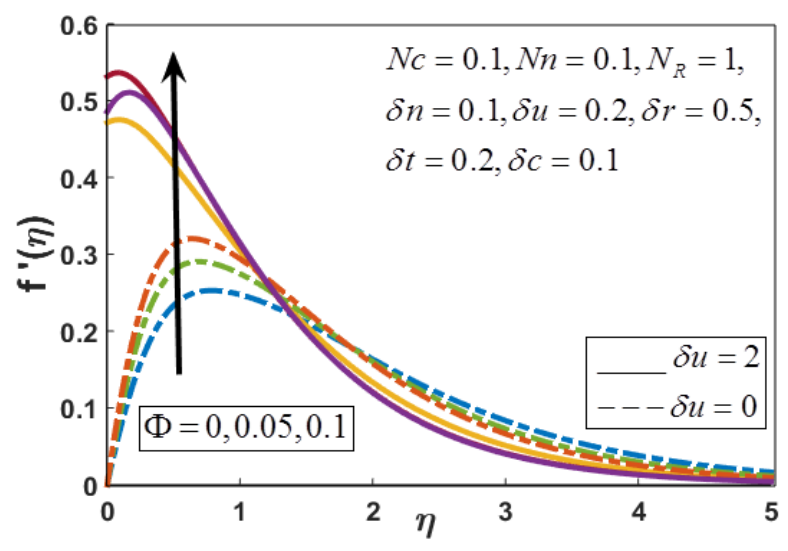

$7(\mathbf{c})$

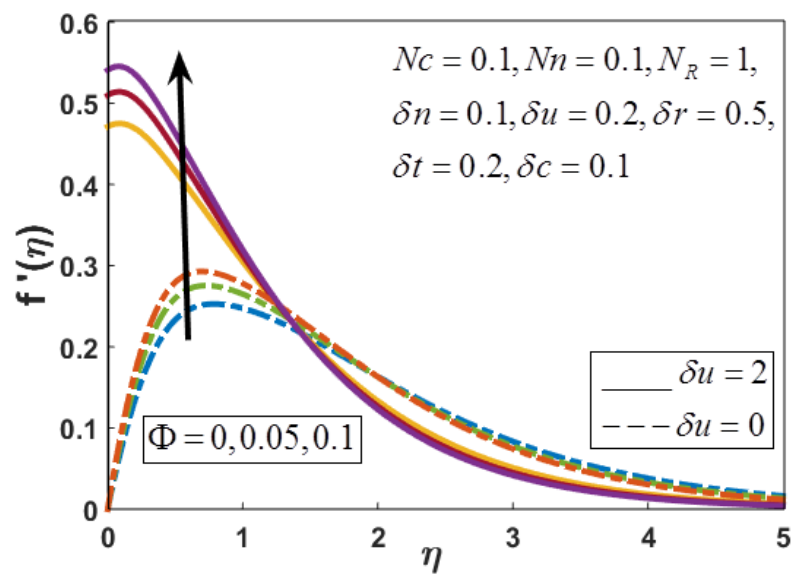

7(b)

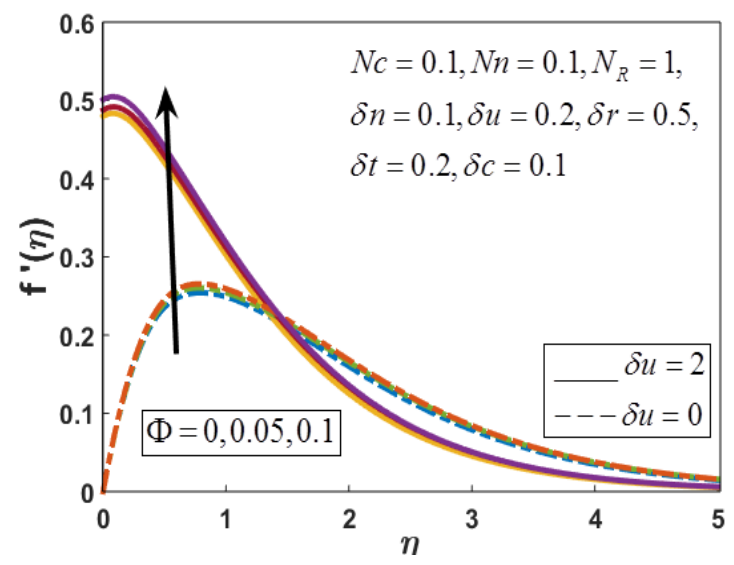

$7(d)$

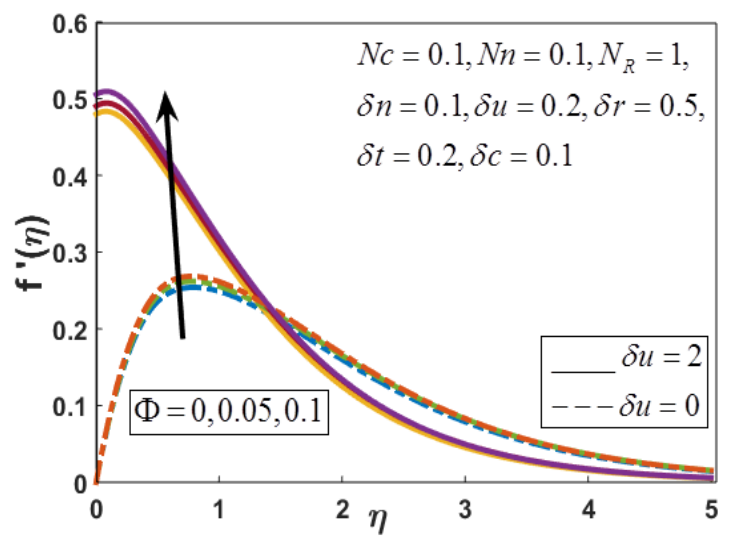

Figure 7:Effects of $\delta_{u}$ and $\Phi$ on tangential velocity profiles for (a) Copper nanofluid,(b) Alumina nanofluid, (c) Copper Oxide nanofluid, and(d) Titanium Oxide nanofluid.

Fig. 7 shows the variation of the tangential velocity profile $f^{\prime}$ for ethylene glycol base fluid containing different nanoparticles i.e. Copper, Alumina, Copper Oxide and Titanium Oxide, for tangential slip parameter $\delta_{u}$ and nanoparticle volume fraction $\Phi$. Tangential profiles are parabolic-they ascend from the cone surface, attain a maximum a short distance therefrom, and then descend smoothly to vanish in the free stream with the increase of both tangential slip parameter and nanoparticle volume fraction. It is observed that the enhancement near the wall is more dominant for copper and copper oxide nanoparticle rather than the other two nanoparticles. 
8(a)

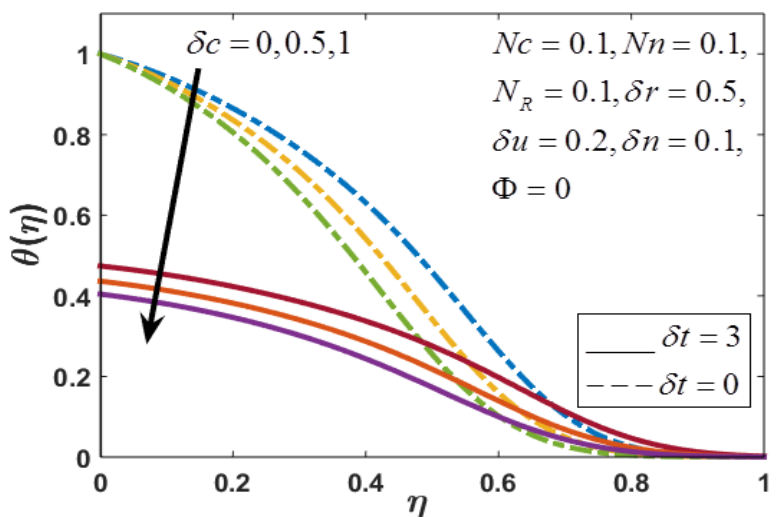

8(c)

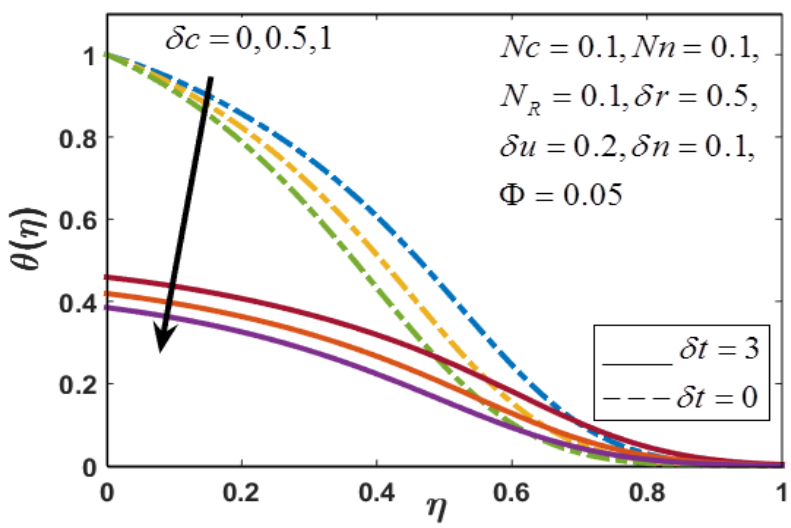

8(b)

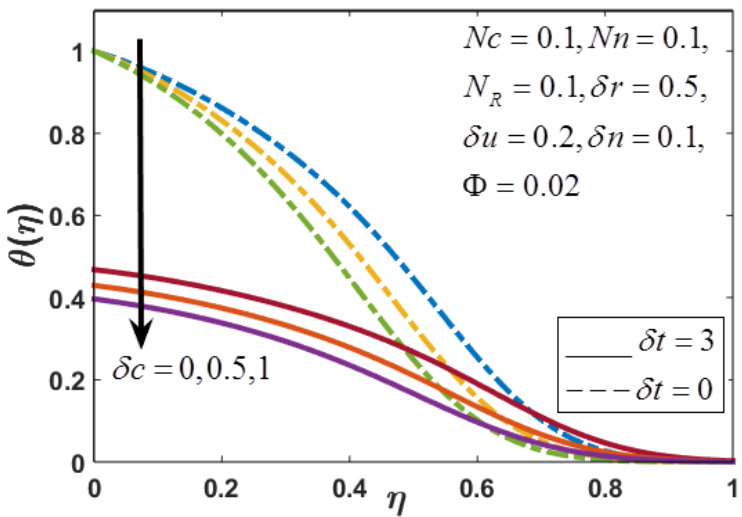

8(d)

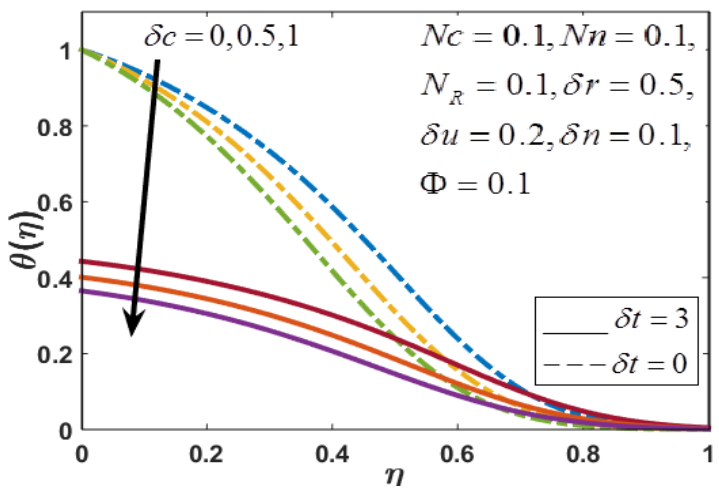

Figure 8: Effects of $\delta_{t}$ and $\delta_{c}$ on temperature profiles for Titanium oxide nanofluid for different nanoparticle volume fraction (a) $\Phi=0$, (b) $\Phi=0.02$, (c) $\Phi=0.05$ and (d) $\Phi=0.1$.

Fig. 8 displays that the microorganism species number density profiles varies very little for the variation of nanoparticles volume fraction in ethylene glycol base Copper Oxide nanofluid. It is enhanced with the higher values of swirl slip parameter but decays with an increase of tangential slip parameter. 


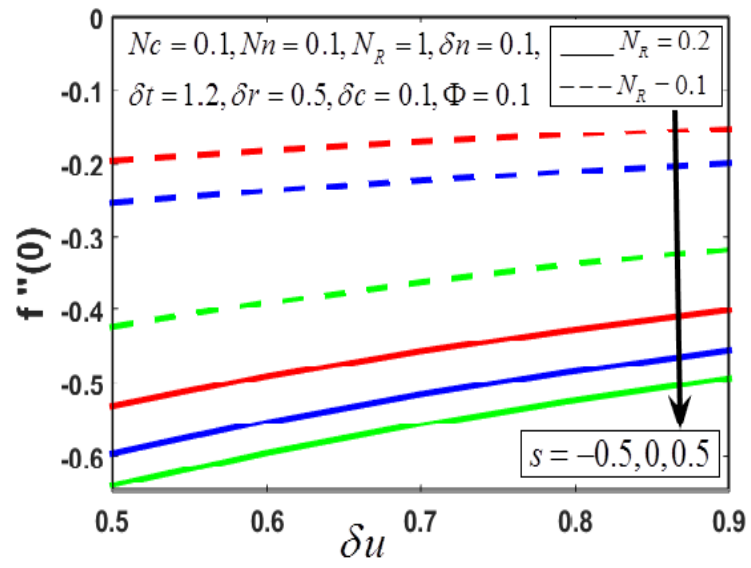

10(a)

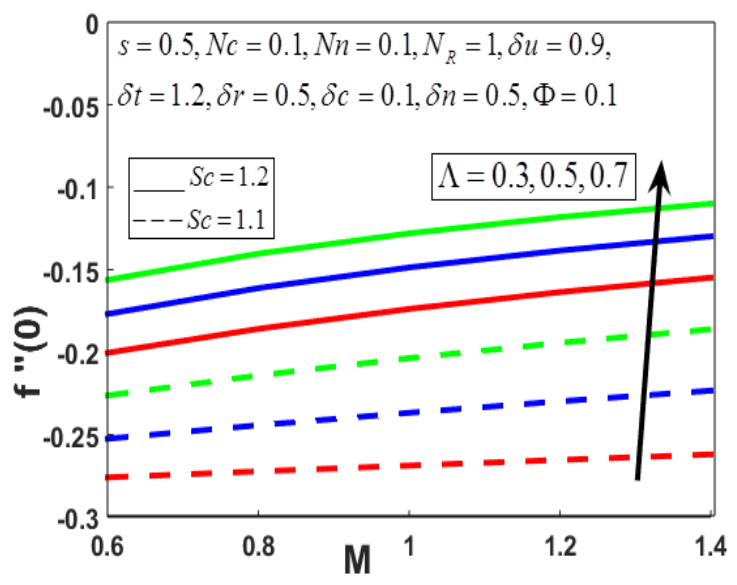

10(b)

Figure 9 : Variations of $C_{f_{\bar{x}}}$ for $C u O$ nanofluid (a) with $s, N_{R}$ and $\delta_{u}$, (b) with $M, S c$ and $\Lambda$.

Fig. 9(a) depicts the variation of skin friction coefficient with tangential slip parameter, suction/injection parameter and rotational (spin) parameter. Skin friction coefficients decreases as both the rotational and suction/injection parameter increase, whereas it increases as tangential slip parameter increases. Fig. 9(b) depicts the variation of skin friction coefficient with magnetic parameter, Schmidt number and magnetic field parameter. Skin friction coefficients increase consistently with an increase in magnetic parameter, Schmidt number and magnetic field parameter.
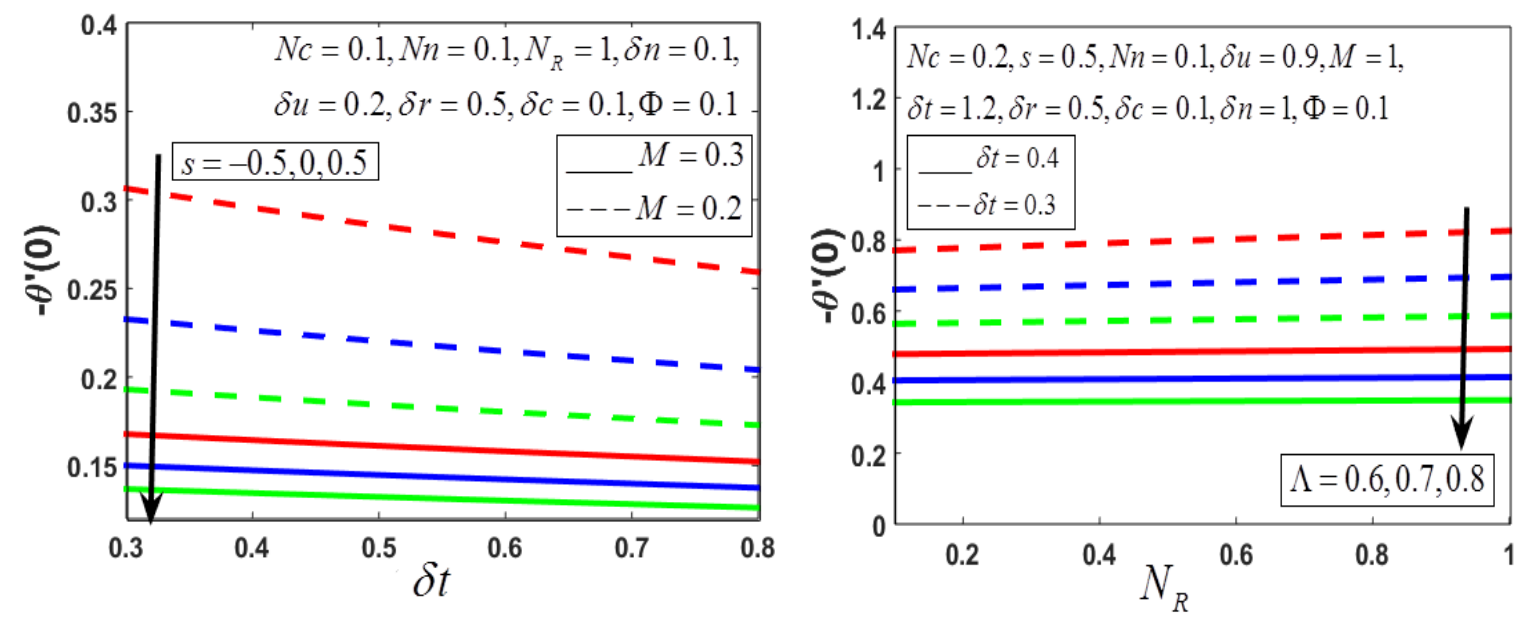

10(a)

10(b)

Figure 10 : Variations of $N u_{\bar{x}}$ for $\mathrm{CuO}$ nanofluid (a) with $\delta_{t}, s$ and $M$ (b) $N_{R}, \delta_{t}$ and $\Lambda$ 
Fig. 10(a) presents the variation of Nusselt number for different values of thermal slip parameter, suction/injection parameter and magnetic parameter. Nusselt number decreases as thermal slip parameter, suction/injection parameter and magnetic parameter all increase. Fig. 10(b) presents the variation in Nusselt number for different values of rotational (spin) parameter, thermal slip parameter and magnetic field parameter. Nusselt number increases with the increase of rotational parameter whereas it decreases with greater values of thermal slip parameter and magnetic field parameter.
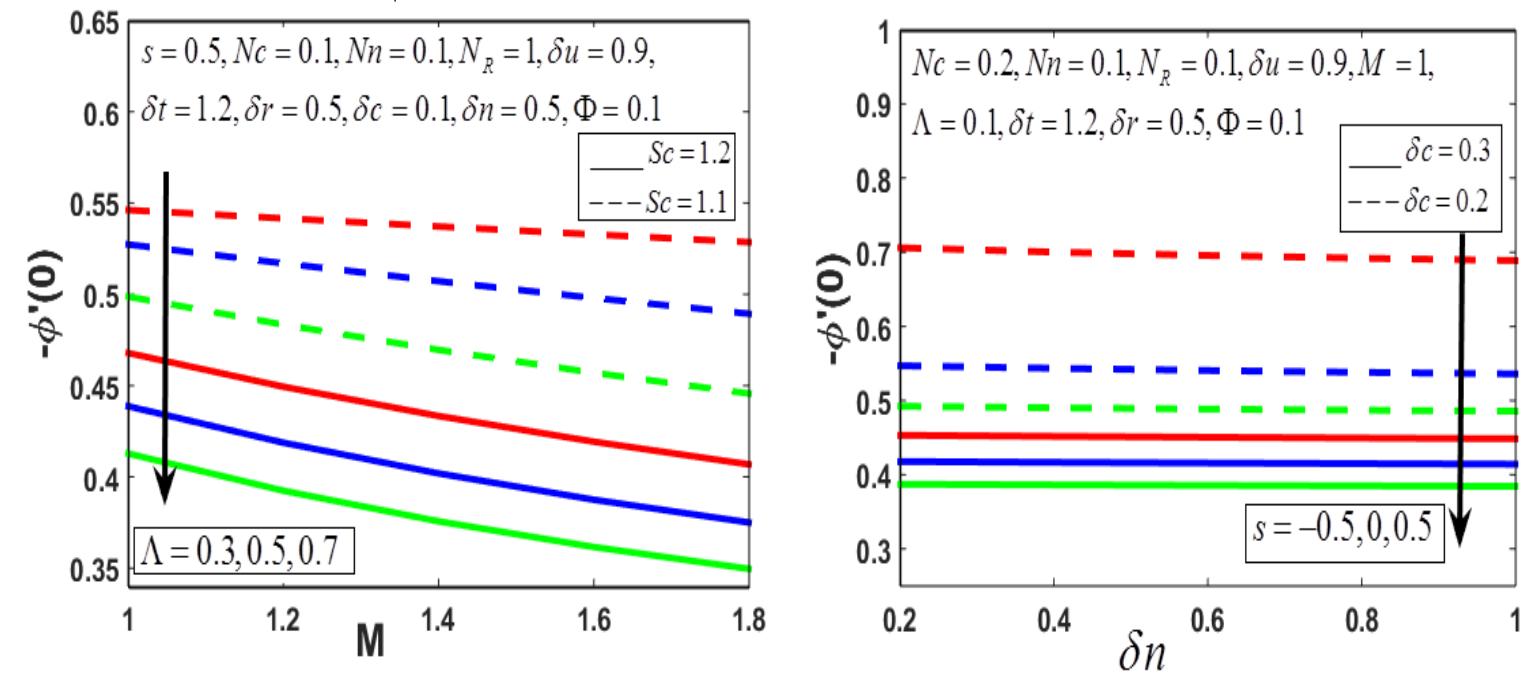

11(a)

11(b)

Figure 11 : Variations of $S h_{\bar{x}}$ for $C u O$ nanofluid (a) with $M, S c$ and $\Lambda$, (b) with $\delta_{n}, \delta_{c}$ and $s$

Fig. 11(a) presents the variation of Sherwood number for different values of magnetic parameter, Schmidt number and magnetic field parameter. Sherwood number decreases as magnetic parameter, Schmidt number and magnetic field parameter increases. Fig. 11(b) presents the variation of Sherwood number for different values of microorganism slip parameter, mass slip parameter and suction/injection. Sherwood number decreases very 
weakly with increasing micro-organism slip effect. However it is strongly reduced with injection and increasing mass slip parameter.

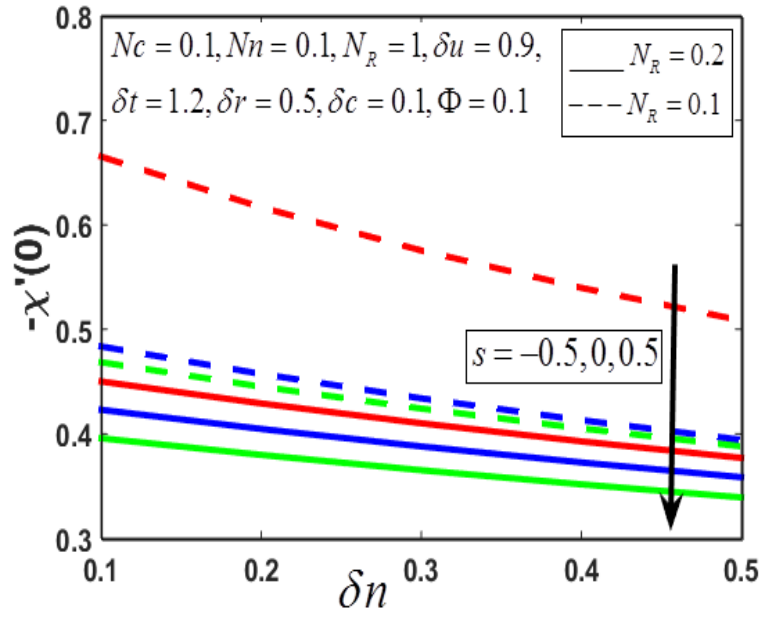

12(a)

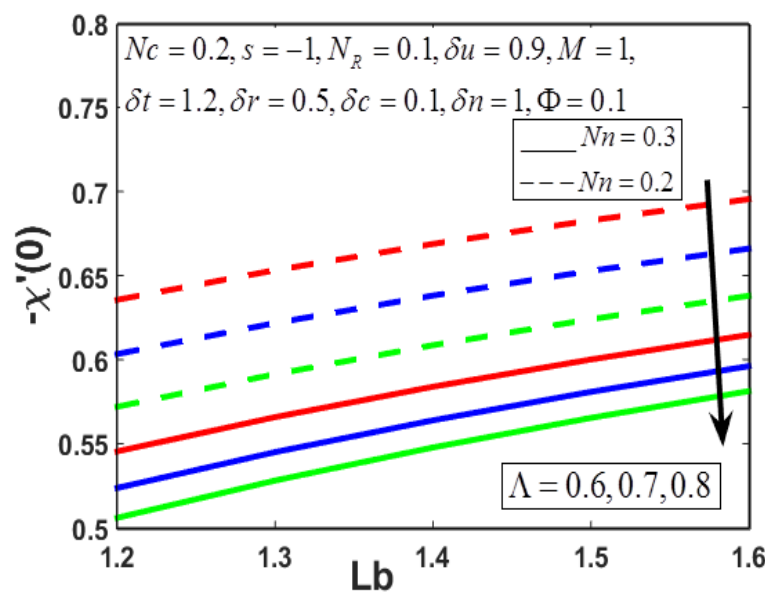

12(b)

Figure 12: Variations of $N n_{\bar{x}}$ for $C u O$ nanofluid (a) $\delta_{n}, s$ and $N_{R}$, (b) $L b, N_{n}$ and $\Lambda$.

Fig. 12(a) presents the variation of density number of motile microorganism for different values of microorganism slip parameter, suction/injection parameter and rotational (spin) parameter. Density number of motile microorganism decreases rapidly with an increase in either microorganism slip parameter, suction/injection parameter or rotational (spin) parameter increases. Fig. 12(b) presents the variation of density number of motile microorganism for different values of Lewis number, microorganism to thermal buoyancy parameter and magnetic field parameter. It increases with the increase of Lewis number, but decreases with the increase of microorganism to thermal buoyancy parameter and magnetic field parameter.

Table 4: The effect of different nanoparticles volume fraction on skin friction and Nusselt number.

\begin{tabular}{|l|l|l|l|l|l|l|l|l|}
\hline \multicolumn{7}{|c|}{$\operatorname{Pr}=151 \& N_{R}=1$} \\
\hline$\Phi$ & nanoparticles & $A_{0}$ & $A_{1}$ & $A_{2}$ & $A_{3}$ & $A_{4}$ & $f^{\prime \prime}(0)$ & $-\theta^{\prime}(0)$ \\
\hline & & & & & & & & \\
\hline
\end{tabular}




\begin{tabular}{|l|l|l|l|l|l|l|l|l|}
\hline 0 & $\mathrm{Cu}$ & 1 & 1 & 1 & 1 & 1 & 0.271646545 & 0.906200551 \\
\hline 0 & $\mathrm{CuO}$ & 1 & 1 & 1 & 1 & 1 & 0.271646545 & 0.906200551 \\
\hline 0 & $\mathrm{AlO} 3$ & 1 & 1 & 1 & 1 & 1 & 0.271646545 & 0.906200551 \\
\hline 0 & $\mathrm{TiO} 2$ & 1 & 1 & 1 & 1 & 1 & 0.271646545 & 0.906200551 \\
\hline 0.02 & $\mathrm{Cu}$ & .092175 & 1.123 & 1.21095 & 1.22826 & 0.87635 & 0.30181714 & 0.90258352 \\
\hline 0.02 & $\mathrm{CuO}$ & 0.95861 & 1.07696 & 1.1644 & 1.11402 & 0.91139 & 0.286192761 & 0.902078245 \\
\hline 0.02 & $\mathrm{AlO} 3$ & 1.0002 & 1.03155 & 1.11597 & 1.11975 & 0.95094 & 0.270514009 & 0.901179482 \\
\hline 0.02 & $\mathrm{TiO} 2$ & 0.99542 & 1.03663 & 1.12133 & 1.11396 & 0.94639 & 0.272238714 & 0.901482630 \\
\hline 0.05 & $\mathrm{Cu}$ & 0.84038 & 1.29912 & 1.56635 & 1.31354 & 0.73923 & 0.338216976 & 0.896549935 \\
\hline 0.05 & $\mathrm{CuO}$ & 0.91453 & 1.18566 & 1.43932 & 1.30159 & 0.80447 & 0.301873778 & 0.895471507 \\
\hline 0.05 & $\mathrm{AlO} 3$ & 1.00693 & 1.07518 & 1.30724 & 1.3181 & 0.88575 & 0.266059844 & 0.893312709 \\
\hline 0.05 & $\mathrm{TiO} 2$ & 0.9958 & 1.08756 & 1.32187 & 1.30188 & 0.87595 & 0.894074654 & 0.894074654 \\
\hline 0.1 & $\mathrm{Cu}$ & 0.76303 & 1.57025 & 2.27399 & 1.69885 & 0.58634 & 0.884845175 & 0.884845175 \\
\hline 0.1 & $\mathrm{CuO}$ & 0.87567 & 1.34888 & 1.98147 & 1.66913 & 0.6729 & 0.312730950 & 0.883123456 \\
\hline 0.1 & $\mathrm{Al} 2 \mathrm{O} 3$ & 1.03447 & 1.13806 & 1.67729 & 1.71089 & 0.79493 & 0.252279850 & 0.879003451 \\
\hline 0.1 & $\mathrm{TiO} 2$ & 1.01412 & 1.16173 & 1.71098 & 1.67077 & 0.77928 & 0.258840697 & 0.880582038 \\
\hline
\end{tabular}

Table 4 shows that with the increase of nanoparticle volume fraction the skin friction coefficient and the heat transfer rate decreases for different nanoparticles. It is further found that both the skin friction and heat transfer rates attain maximum values for $\mathrm{Cu}$ nanoparticles and minimum values for $\mathrm{TiO}_{2}$ nanoparticles.

\section{CONCLUSIONS}

The effect of Stefan blowing on steady bioconvection magnetic boundary layer anisotropic slip flow past a rotating cone to a nanofluid is investigated theoretically. The partial differential equations for mass, momentum, energy, nano-particle species and micro-organisms species conservation are rendered into self-similar form with appropriate transformations, subject to physically realistic boundary conditions. Using BVP5C, numerical solutions are obtained for the emerging ordinary differential boundary value problem. The model, method and results are validated by comparing with previous solutions. Based on the numerical results, the important phenomena observed are:

- With greater magnetic field, heat, mass and motile microorganism transfer rates are reduced whereas skin friction coefficient is increased. 
- The skin friction coefficient, Nusselt number, Sherwood number and density number of motile microorganism are found to be reduced with greater injection i.e. stronger blowing effect.

- With higher values of rotational parameter, heat and microorganism transfer rates are decreased whereas skin friction coefficient rises.

- The tangential slip parameter and Schmidt number elevates skin friction coefficient but decays mass transfer rate.

\section{ACKNOWLEDGEMENTS}

The authors acknowledge financial support from Universiti Sains Malaysia, RU Grant 1001/PMATHS/8011013.

\section{Reference}

[1] S. Akbarzadeh, M. Farhadi, K. Sedighi, and M. Ebrahimi, Experimental investigation on the thermal conductivity and viscosity of zno nanofluid and development of new correlations, Transp. Phenom. Nano Micro Scales. 2 (2014) 149-160.

[2] H.F. Oztop, and E. Abu-Nada, Numerical study of natural convection in partially heated rectangular enclosures filled with nanofluids, Int. J. Heat Fluid Flow. 29 (2008) $1326-1336$.

[3] R. Mebrouk, M. Kadja, M. Lachi, and S. Fohanno, Numerical study of natural turbulent convection of nanofluids in a tall cavity heated from below, Int. J. Therm. Sci. 20 (2016) 2051-2064.

[4] Y.S. Lin, P.Y. Hsiao, and C.C. Chieng, Thermophysical characteristics of ethylene glycol-based copper nanofluids using nonequilibrium and equilibrium methods, Int. J. Therm. Sci. 62 (2012) 56-60.

[5] S.M. Aminossadati, and B. Ghasemi, Enhanced natural convection in an isosceles triangular enclosure filled with a nanofluid, Comput. Math. with Appl. 61 (2011) 
$1739-1753$.

[6] E. Abu-Nada, and A.J. Chamkha, Effect of nanofluid variable properties on natural convection in enclosures filled with a CuOeEGeWater nanofluid, Int. J. Therm. Sci. 49 (2010) 2339-1352.

[7] Y.L. Wei Yu, Huaqing Xie, and Lifei Chen, Investigation of thermal conductivity and viscosity of ethylene glycol based ZnO nanofluid, Thermochim. Acta. 491 (2009) 9296.

[8] M.B. Ben Hamida, and K. Charrada, Natural convection heat transfer in an enclosure filled with an ethylene glycol—copper nanofluid under magnetic fields, Numer. Heat Transf. Part A Appl. 67 (2015) 902-920.

[9] N.A. Amirsom, M.J. Uddin, and A.I. Ismail, Three dimensional stagnation point flow of bionanofluid with variable transport properties, Alexandria Eng. J. 55 (2016) 19831993.

[10] N.A. Latiff, M.J. Uddin, and A.I.M. Ismail, Stefan blowing effect on bioconvective flow of nanofluid over a solid rotating stretchable disk, Propuls. Power Res. 5 (2016) $267-278$.

[11] A. V Kuznetsov, Non-oscillatory and oscillatory nanofluid bio-thermal convection in a horizontal layer of finite depth, Eur. J. Mech. B/Fluids. 30 (2011) 156-165.

[12] A. V. Kuznetsov, Nanofluid bioconvection: interaction of microorganisms oxytactic upswimming, nanoparticle distribution, and heating/cooling from below, Theor. Comput. Fluid Dyn. 26 (2012) 291-310.

[13] A.V. Kuznetsov, and D.A. Nield, Natural convective boundary layer flow of a 
nanofluid past a vertical plate: A revised model, Int. J. Therm. Sci. 77 (2014) 126-129.

[14] T. Fang, and H. Tao, Unsteady viscous flow over a rotating stretchable disk with deceleration, Commun. Nonlinear Sci. Numer. Simul. 17 (2012) 5064-5072.

[15] H. Xu, Lie group analysis of a nanofluid bioconvection flow past a vertical flat surface with an outer power-law stream, J. Heat Transfer. 137 (2015) 41101.

[16] T. Watanabe, ACTA MECHANICA Free convection boundary layer flow with uniform suction or injection over a cone, Aeta Mech. 87 (1991) 1-9.

[17] K. Bhattacharyya, and G.C. Layek, Effects of suction/blowing on steady boundary layer stagnation-point flow and heat transfer towards a shrinking sheet with thermal radiation, Int. J. Heat Mass Transf. 54 (2011) 302-307.

[18] D. Pal, and H. Mondal, Effects of Soret Dufour, chemical reaction and thermal radiation on MHD non-Darcy unsteady mixed convective heat and mass transfer over a stretching sheet, Commun. Nonlinear Sci. Numer. Simul. 16 (2011) 1942-1958.

[19] T. Fang, and W. Jing, Flow, heat, and species transfer over a stretching plate considering coupled Stefan blowing effects from species transfer, Commun. Nonlinear Sci. Numer. Simul. 19 (2014) 3086-3097.

[20] G. Nellis, Heat Transfer | Thermal Fluids Engineering, Cambridge University Press, UK, 2016.

[21] H. John Lienhard IV, A Heat Transfer Textbook, Third ed., Cambridge, MA Phlogist. Press, 2008.

[22] J. Buongiorno, Convective Transport in Nanofluids, J. Heat Transfer. 128 (2006) 240.

[23] A.M. Rohni, S. Ahmad, A. Izani, M. Ismail, and I. Pop, Flow and heat transfer over an 
unsteady shrinking sheet with suction in a nanofluid using Buongiorno's model, Int. Commun. Heat Mass Transf. 43 (2013) 75-80.

[24] M.R. Hajmohammadi, H. Maleki, G. Lorenzini, and S.S. Nourazar, Effects of Cu and Ag nano-particles on flow and heat transfer from permeable surfaces, Adv. Powder Technol. 26 (2015) 193-199.

[25] C.Y. Wang, Stagnation flow on a plate with anisotropic slip, Eur. J. Mech. B/Fluids. 38 (2013) 73-77.

[26] C.O. Ng, and C.Y. Wang, Effective slip for Stokes flow over a surface patterned with two-or three-dimensional protrusions, Fluid Dyn. Res. 43 (2011) 65504-20.

[27] C.O. Ng, and C.Y. Wang, Stokes shear flow over a grating: Implications for superhydrophobic slip, Phys. Fluids. 21 (2009) 13602.

[28] X. Tian, M.E. Itkis, E.B. Bekyarova, and R.C. Haddon, Anisotropic Thermal and electrical properties of thin thermal interface layers of graphite nanoplatelet-based composites, Sci. Rep. 3 (2013) 30-35.

[29] M.J. Uddin, W.A. Khan, A.I.M. Ismail, and O. Anwar Bég, Computational study of three-dimensional stagnation point nanofluid bioconvection flow on a moving surface with anisotropic slip and thermal jump effect, ASME J. Heat Transfer, 138 (2016) 104502.

[30] A. Raees, M. Raees-ul-Haq, H. Xu, and Q. Sun, Three-dimensional stagnation flow of a nanofluid containing both nanoparticles and microorganisms on a moving surface with anisotropic slip, Appl. Math. Model, 40 (2016) 4136-4150.

[31] R. Ravindran, S. Roy, and E. Momoniat, Effects of injection (suction) on a steady 
mixed convection boundary layer flow over a vertical cone, Int. J. Numer. Methods Heat Fluid Flow, 19 (2009) 432-444.

[32] H.S. Takhar, A.J. Chamkha, and G. Nath, Unsteady mixed convection flow from a rotating vertical cone with a magnetic field, Heat Mass Transf., 39 (2003) 297-304.

[33] R.G. Hering, and R.J. Grosh, Laminar free convection from a non-isothermal cone, Int. J. Heat Mass Transf., 5 (1962) 1059-1068.

[34] S. Roy, Free convection from a vertical cone at high prandtl numbers, J. Heat Transfer, $96(1974) 115$.

[35] F.N. Lin, Laminar free convection from a vertical cone with uniform surface heat flux, Lett. Heat Mass Transf. 3 (1976) 49-58.

[36] I. Pop, Compressibility effects in laminar free convection from a vertical cone, Appl. Sci. Res. 48 (1991) 71-82.

[37] D. Anilkumar, and S. Roy, Unsteady mixed convection flow on a rotating cone in a rotating fluid, Appl. Math. Comput. 155 (2004) 545-561.

[38] P. Bapuji, A.K. Ekambavanan, and A.I. Pop, Finite difference analysis of laminar free convection flow past a non isothermal vertical cone, Heat Mass Transf. 44 (2007) 517526.

[39] A.J. Chamkha, and A. Al-Mudhaf, Unsteady heat and mass transfer from a rotating vertical cone with a magnetic field and heat generation or absorption effects, Int. J. Therm. Sci. 44 (2005) 267-276.

[40] M.A. Hossain, K. Khanafer, and K. Vafai, The effect of radiation on free convection flow of fluid with variable viscosity from a porous vertical plate, Int. J. Therm. Sci. 40 
(2001) 115-124.

[41] M. Narayana, F.G. Awad, and P. Sibanda, Free magnetohydrodynamic flow and convection from a vertical spinning cone with cross-diffusion effects, Appl. Math. Model. 37 (2013) 2662-2678.

[42] Vanita, and A. Kumar, Numerical study of effect of induced magnetic field on transient natural convection over a vertical cone, Alexandria Eng. J. 55 (2016) 12111223.

[43] Hayat, T., M. Waqas, M. Ijaz Khan, A. Alsaedi, and S.A. Shehzad, Magnetohydrodynamic flow of burgers fluid with heat source and power law heat flux, Chinese Journal of Physics, 55, no. 2 (2017) 318-330.

[44] T. Hayat, M. Zubair, M. Waqas, A. Alsaedi, and M. Ayub, Application of non-fourier heat flux theory in thermally stratified flow of second grade liquid with variable properties,Chinese Journal of Physics 55, no. 2 (2017) 230-241.

[45] K. Das, N. Acharya, and P.K. Kundu, The onset of nanofluid flow past a convectively heated shrinking sheet in presence of heat source/sink: A Lie group approach, Appl. Therm. Eng., 103 (2016) 38-46.

[46] S. S. Giri, K. Das, and P.K. Kundu, Stefan blowing effects on MHD bioconvection flow of a nanofluid in the presence of gyrotactic microorganisms with active and passive nanoparticles flux, The European Phy. J. Plus, 132.2 (2017) 101.

[47] N. Acharya, K. Das, and P.K. Kundu, Framing the effects of solar radiation on magneto- hydrodynamics bioconvection nanofluid flow in presence of gyrotactic microorganisms, Journal of Molecular Liquids, 222 (2016) 28-37.

[48] O.A. Beg, M.J. Uddin, T. Beg, and R.R. Gorla, Numerical simulation of self-similar thermal convection from a spinning cone in anisotropic porous medium, J. Hydrodyn. 
Ser. B. 28 (2016) 184-194.

[49] M.J. Uddin, O.A. Beg, and T.A. Beg, Stefan blowing, Navier slip, and radiation effects on thermo-solutal convection from a spinning cone in an anisotropic porous medium, J. Porous Med.. 19 (2016) 617-633.

[50] W.A. Khan, M.J. Uddin, and A.I.M. Ismail, Multiple slip effects on unsteady MHD rear stagnation point flow of nanofluids in a Darcian porous medium, J. Porous Med. 18 (2015) 665-678.

[51] K. Vajravelu, K.V. Prasad, J. Lee, C. Lee, I. Pop, and R.A. Van Gorder, Convective heat transfer in the flow of viscous $\mathrm{Ag}$-water and $\mathrm{Cu}$-water nanofluids over a stretching surface, Int. J. Therm. Sci. 50 (2011) 843-851.

[52] M. Sheikholeslami, M. Hatami, and D.D. Ganji, Analytical investigation of MHD nanofluid flow in a semi-porous channel, Powder Technol. 246 (2013) 327-336.

[53] W.N. Mutuku, Ethylene glycol (EG)-based nanofluids as a coolant for automotive radiator, Asia Pacific J. Comput. Eng. 3 (2016) 1.

[54] M.C. Ece, Free convection flow about a vertical spinning cone under a magnetic field, Appl. Math. Comput. 179 (2006) 231-242.

[55] E. Hairer, C. Lubich, and G. Wanner, Geometric Numerical Integration : StructurePreserving Algorithms for Ordinary Differential Equations, Springer, 2006. 


\begin{tabular}{|c|c|}
\hline \multicolumn{2}{|c|}{ Nomenclature } \\
\hline$b$ & chemotactic constant \\
\hline$b_{0}$ & function of $x$ \\
\hline$B$ & $\begin{array}{l}\text { magnetic field imposed along the } \\
\bar{y} \text { axis, }\end{array}$ \\
\hline$B_{0}$ & constant magnetic field \\
\hline$C$ & fluid concentration \\
\hline$C_{w}$ & cone surface concentration \\
\hline$C_{\infty}$ & free stream concentration \\
\hline$D$ & mass diffusivity of the fluid \\
\hline$D_{B}$ & Brownian diffusion coefficient \\
\hline$D_{n}$ & diffusivity coefficient \\
\hline$D_{1}$ & thermal slip factor \\
\hline$E_{1}$ & mass slip factor \\
\hline$F_{1}$ & microorganism slip factor \\
\hline$f$ & boundary-layer stream function \\
\hline$g$ & gravitational acceleration \\
\hline$G r$ & Grashof number \\
\hline$h$ & $\begin{array}{l}\text { boundary-layer rotational (swirl) } \\
\text { velocity }\end{array}$ \\
\hline$k_{f}$ & $\begin{array}{l}\text { effective thermal conductivity of } \\
\text { the fluid }\end{array}$ \\
\hline$k_{s}$ & $\begin{array}{l}\text { effective thermal conductivity of } \\
\text { the solid fraction }\end{array}$ \\
\hline$k_{n f}$ & $\begin{array}{l}\text { effective thermal conductivity of } \\
\text { the nanofluid }\end{array}$ \\
\hline$L$ & reference scale length \\
\hline$L b$ & Lewis number \\
\hline$M$ & magnetic parameter \\
\hline$n$ & $\begin{array}{l}\text { number of motile micro- } \\
\text { organisms }\end{array}$ \\
\hline$n_{w}$ & $\begin{array}{l}\text { number of motile micro- } \\
\text { organisms at the surface of the } \\
\text { cone }\end{array}$ \\
\hline$n_{\infty}$ & $\begin{array}{l}\text { number of motile micro- } \\
\text { organisms at the free stream }\end{array}$ \\
\hline$N_{C}$ & $\begin{array}{l}\text { concentration-to-thermal- } \\
\text { buoyancy ratio parameter }\end{array}$ \\
\hline$N_{n}$ & $\begin{array}{l}\text { microorganism-to-thermal- } \\
\text { buoyancy ratio parameter, }\end{array}$ \\
\hline$N_{R}$ & rotational (spin) parameter \\
\hline$N_{1}$ & $\begin{array}{l}\text { velocity slip factor for the } u \\
\text { velocity component }\end{array}$ \\
\hline$N_{2}$ & $\begin{array}{l}\text { velocity slip factor for the } w \\
\text { velocity component }\end{array}$ \\
\hline
\end{tabular}

\begin{tabular}{|c|c|}
\hline $\mathrm{Nb}$ & Brownian motion parameter \\
\hline$N t$ & thermophoresis parameter \\
\hline$N_{n_{\bar{x}}}$ & $\begin{array}{l}\text { local density number of motile } \\
\text { microorganisms, }(-)\end{array}$ \\
\hline$N_{u_{\bar{x}}}$ & local Nusselt number \\
\hline$P e$ & Péclet number \\
\hline $\operatorname{Pr}$ & Prandtl number \\
\hline$r$ & transformed local cone radius \\
\hline $\operatorname{Re}$ & rational Reynolds number \\
\hline $\bar{r}$ & radial coordinate \\
\hline$s$ & $\begin{array}{l}\text { suction or injection/ blowing } \\
\text { parameter }\end{array}$ \\
\hline$S c$ & Schmidt number \\
\hline$S h_{\bar{x}}$ & local Sherwood number \\
\hline$t$ & dimensional time \\
\hline$T$ & fluid temperature \\
\hline$T_{w}$ & cone surface temperature \\
\hline$T_{\infty}$ & free stream temperature \\
\hline$u$ & transformed $\bar{x}$ velocity \\
\hline$U$ & reference velocity \\
\hline $\bar{u}$ & $\begin{array}{l}\text { velocity component in the } \bar{x} \\
\text { direction }\end{array}$ \\
\hline$v$ & transformed $\bar{y}$ velocity \\
\hline $\bar{v}$ & $\begin{array}{l}\text { velocity component in the } \bar{y} \\
\text { direction }\end{array}$ \\
\hline$w$ & transformed $\omega$ velocity \\
\hline$W_{C}$ & maximum cell swimming speed \\
\hline $\bar{w}$ & $\begin{array}{l}\text { velocity component in the } \omega \\
\text { direction }\end{array}$ \\
\hline$x$ & transformed $\bar{x}$ coordinate \\
\hline $\bar{x}$ & $\begin{array}{l}\text { coordinate parallel to the cone } \\
\text { surface }\end{array}$ \\
\hline$y$ & transformed $\bar{y}$ coordinate \\
\hline $\bar{y}$ & $\begin{array}{l}\text { coordinate normal to the cone } \\
\text { surface }\end{array}$ \\
\hline
\end{tabular}

\section{Greek Letters}

\begin{tabular}{|l|l|}
\hline$\alpha_{n f}$ & $\begin{array}{l}\text { thermal diffusivity of the } \\
\text { nanofluid }\end{array}$ \\
\hline
\end{tabular}




\begin{tabular}{|c|c|}
\hline$\beta_{c}$ & $\begin{array}{l}\text { coefficient of the mass } \\
\text { expansion of the fluid }\end{array}$ \\
\hline$\beta_{n}$ & $\begin{array}{llr}\text { coefficient } & \text { of } & \text { the } \\
\text { microorganism } & \text { expansion } \\
\text { the fluid } & \end{array}$ \\
\hline$\beta_{T}$ & $\begin{array}{l}\text { coefficient of the thermal } \\
\text { expansion of the fluid, }\end{array}$ \\
\hline$\gamma$ & semi vertex cone of the angle \\
\hline$\theta$ & boundary-layer temperature \\
\hline$\theta$ & $\begin{array}{l}\text { non-dimensional temperature } \\
\text { function }\end{array}$ \\
\hline$\Phi$ & nanoparticle volume fraction \\
\hline$\phi$ & boundary-layer concentration \\
\hline$\phi$ & $\begin{array}{l}\text { non-dimensional concentration } \\
\text { function }\end{array}$ \\
\hline$\Omega$ & $\begin{array}{l}\text { rotational velocity of the cone } \\
\text { (spin velocity about symmetry } \\
\text { axis) }\end{array}$ \\
\hline$\omega$ & angular coordinate, \\
\hline$\mu_{n f}$ & $\begin{array}{llll}\text { dynamic viscosity } & \text { of the } \\
\text { nanofluid } & & & \end{array}$ \\
\hline$v_{f}$ & kinematic viscosity of the fluid \\
\hline$v_{n f}$ & $\begin{array}{l}\text { kinematic viscosity of the } \\
\text { nanofluid }\end{array}$ \\
\hline$\chi$ & $\begin{array}{l}\text { boundary layer microorganism } \\
\text { species number density }\end{array}$ \\
\hline$\chi$ & $\begin{array}{l}\text { non-dimensional } \\
\text { microorganism function }\end{array}$ \\
\hline$\sigma_{n f}$ & $\begin{array}{l}\text { electric conductivity of the } \\
\text { nanofluid }\end{array}$ \\
\hline$\rho$ & density of the fluid \\
\hline$\rho_{n f}$ & density of the nanofluid \\
\hline$\left(\rho C_{p}\right)_{n f}$ & heat capacity of the nanofluid \\
\hline$\left(\rho \beta_{C}\right)_{n f}$ & $\begin{array}{l}\text { volumetric concentration } \\
\text { expansion of the nanofluid, }\end{array}$ \\
\hline$\left(\rho \beta_{n}\right)_{n f}$ & $\begin{array}{l}\text { volumetric microorganism } \\
\text { expansion of the nanofluid, }\end{array}$ \\
\hline$\left(\rho \beta_{T}\right)_{n f}$ & $\begin{array}{l}\text { volumetric thermal expansion } \\
\text { of the nanofluid, }\end{array}$ \\
\hline$\Lambda$ & magnetic field function, \\
\hline$\delta_{c}$ & mass slip parameter \\
\hline$\delta_{n}$ & microorganism slip parameter \\
\hline & swirl slip parameter \\
\hline
\end{tabular}

\begin{tabular}{|l|l|}
\hline$\delta_{r}$ & \\
\hline$\delta_{t}$ & thermal slip parameter \\
\hline$\delta_{u}$ & tangential slip parameter \\
\hline
\end{tabular}

